ISSN: 0213-2079 - ISSN electrónico: 2386-3889

DOI: https://doi.org/10.14201/shhmo2018401263297

\title{
CREAR ESPACIOS PARA LEER Y PENSAR. LOS ESTUDIOS DE ZARAGOZA EN LOS SIGLOS XVII Y XVIII
}

\section{Creating Spaces to Read and Think. The Studies from Zaragoza during the $17^{\text {th }}$ and $18^{\text {th }}$ Centuries}

\section{Juan POSTIGO VIDAL}

Universidad de Zaragoza

Correo-e: juanpostigovidal@hotmail.com

RESUMEN: La necesidad de encontrar lugares y momentos para el retiro intelectual, hizo que a lo largo de la modernidad fuese configurándose dentro de las casas una nueva clase de espacios destinados a que los miembros de la élite pudiesen desarrollar convenientemente sus actividades culturales y sociales. Este proceso, iniciado en los tiempos del Renacimiento, cobró gran importancia en el siglo XviI, cuando la presencia de estos «estudios» se hizo mucho más notoria y adquirió connotaciones muy distintas. Este trabajo se centra en la ciudad de Zaragoza, y utiliza los inventarios de bienes como fuente predilecta para la observación de las tipologías y la evolución de los estudios a lo largo de la Edad Moderna.

Palabras clave: Privacidad; Intelectualidad; Lujo; Zaragoza; Edad Moderna.

ABSTRACT: The need to find places and moments for intellectual retreat, made throughout modernity was taking shape inside houses a new class of

* Este trabajo se inscribe dentro de los proyectos de investigación Elites políticas y religiosas, sacralidad territorial y hagiografía en la Iglesia hispánica de la Edad Moderna (HAR2014-52434-C5-2-P), Celebrar las glorias. Publicística sagrada y devociones en la Iglesia hispánica de la Edad Moderna (HAR2011-28732-C03-03), ambos con Eliseo Serrano Martín como investigador principal, y al grupo de investigación consolidado Blancas de la Universidad de Zaragoza. 
spaces for members of the elite could conveniently develop their cultural and social activities. This process, begun in Renaissance times, gained great importance and presence in the $17^{\text {th }}$ century, when the presence of these «studies» became much more present and acquired very different connotations. This work focuses on the city of Zaragoza, using inventories of goods as preferred source for observing typologies and evolution of studies throughout the Early Modern Age.

Key words: Privacy; Intellectuality; Luxury; Zaragoza; Early Modern Age.

En el otoño de 1632 dos vecinos de la calle Mayor de Zaragoza tuvieron una pelea muy fuerte provocada en principio por un problema de contigüidad. Quien efectuó la denuncia fue Andrés de Serán, un abogado veterano que aseguraba tener problemas para alcanzar el silencio y la tranquilidad necesarias en su trabajo por los constantes martillazos que le llegaban de la casa adyacente, donde desafortunadamente para él vivía un carpintero ${ }^{1}$. Alegaba el jurista que por derechos forales se le tenía que haber preguntado antes de que el artesano se instalase si estaba o no de acuerdo con la naturaleza del inquilino de al lado, y que las personas como él contaban con el indiscutible derecho a vivir «aislados» del ritmo de la ciudad. Entretanto, el carpintero acusado, Juan Sierra, mostraba sus dudas hacia la afirmación del demandante. ¿Realmente los Fueros decían eso? Pues de ser así, replicaba con destreza, tal artículo se referiría a aquellos jueces y letrados que trabajaban de verdad, y no a esos otros que -como al parecer era el caso de su vecino- vivían holgadamente de sus rentas sin hacer nada más. A lo largo de los más de diez años que llevaba viviendo en esa misma casa y ejerciendo en ese taller en calidad de maestro examinado al mando de varios mancebos y oficiales, Juan Sierra aseguraba no haber visto a su vecino ni una sola vez recibir visitas de trabajo ni organizar en su vivienda reuniones con sus clientes. ¿Qué más le daría entonces que hubiese ruido?

El carpintero no parecía contemplar la posibilidad de que un individuo requiriese -aunque fuese de una forma tan maniática como esta- no solo momentos, sino también un lugar donde poder retirarse a pensar, a leer o a escribir; y de haber sabido que en realidad Andrés de Serán atendía casos de relevancia y bastante secretos fuera de su casa por depender de la Inquisición, muy posiblemente habría persistido en su postura de que para su vecino el silencio no era una necesidad,

1. Archivo Municipal de Zaragoza [en adelante AMZ], Sección Procesos, 0821. 
sino tan solo un antojo absurdo. Además, tanto Sierra como otros hombres del barrio comentaron a las autoridades que antes de llegar él la casa y el taller habían sido habitados por un hornero, un sombrerero y un guarnicionero -trabajadores manuales propensos al ajetreo constante-, y que entonces el demandante nunca se quejó. Es posible que detrás de todo hubiese alguna clase de intolerancia ajena al asunto del ruido, que simplemente se tratase de fricciones personales; o también podría ser que efectivamente Juan Sierra fuese un tipo ruidoso hasta el extremo, mucho más que cualquier otro artesano de la ciudad. Para quienes llevaron este proceso, la clave estaba en comprobar si efectivamente el ruido del taller del artesano podía llegar con fuerza hasta el interior del estudio del abogado, al menos con una intensidad suficiente como para poder impedir la concentración. El propio carpintero juró desde el principio que era imposible que a Andrés de Serán le molestase ningún ruido, decía que de un lugar a otro había «más de un tiro grande de escopeta». Lo mismo declararon otros individuos interrogados. El zapatero de origen francés Juan de la Batud calculaba unos cien pasos entre las dos habitaciones, y el pavonador y dorador Francisco Ribera llegaba incluso a doblar esa distancia.

El testimonio más revelador lo dio en cambio un notario llamado Lorenzo Calvo, quien además era infanzón y donado de la orden de San Juan de Jerusalén. Según sus propias declaraciones, en una ocasión llegó a visitar la casa del abogado, siendo invitado a entrar en su estudio. El notario no pudo evitar incluir en su relato lo mucho que le impresionó la enorme librería de Andrés de Serán, pero seguidamente pasó a desmentir la duda sobre el ruido ofreciendo una descripción de cómo estaban distribuidos los espacios en las dos viviendas. Sabía por haber solicitado sus servicios varias veces que el taller del carpintero estaba a pie de calle, y que el nivel superior quedaba destinado a acoger las estancias de habitación de Sierra. Una de las paredes de aquel obrador daba efectivamente al patio de la casa del abogado; este contaba en su parte más alejada con un pequeño huerto, y justo encima de las plantas del mismo, en los entresuelos de la casa, se hallaba el famoso estudio de la discordia, que tenía al menos una ventana orientada hacia el patio. Si nos atenemos a las apreciaciones de los testigos realmente parece que las quejas del abogado eran algo excesivas, pues el estudio no lindaba directamente con la botiga, sino que entre los dos espacios se interponía un ancho patio con un pequeño huerto. Claro que, por otra parte, y tratando de encontrarle una lógica a las exigencias de Andrés de Serán, es posible que lo que este hombre buscase infructuosamente fuese un entorno calmo, comparable quizás al de un monasterio, para poder leer sus libros en un ambiente de silencio total. De ser así el trasfondo de la cuestión, el jurista estaría soñando con algo imposible de alcanzar en una zona urbana tan céntrica como aquella y en la que había un movimiento tan constante y acelerado. 
Pero lo realmente significativo en cualquier caso sería que tal requerimiento -el cual podía ser más o menos comprendido por el resto de individuos- llegó a ser en esta ocasión exteriorizado y defendido con una convicción absoluta, dando a entender que el silencio era para ciertas personas un derecho inquebrantable.

La conquista de la individualidad, la apropiación de un espacio personal alejado de miradas y participaciones externas de diversa naturaleza, fueron hitos de gran relevancia cultural que comenzaron a tomar forma en los albores de la moderni$\mathrm{dad}^{2}$. Puede suponerse que la inclusión primera de estos remansos de paz en los interiores domésticos tuvo más que ver precisamente con la intención de acumular y exhibir objetos determinados que con la pretensión de alcanzar la soledad, pero no es menos cierto que andando el tiempo algunos de los principales alicientes con que contaban estas piezas extraídas de los ambientes conventuales acabaron convirtiéndose en necesidades ineludibles para una parte muy significativa de la población ${ }^{3}$. En 1632 el jurista Andrés de Serán osaba presentarse ante la justicia exigiendo que el vecino carpintero abandonase su hogar porque los ruidos salidos del taller le molestaban a él, que llevaba más tiempo viviendo allí. En su relato, el abogado partía de su propia necesidad del silencio para poder ejercer su labor, trataba en todo momento de hacer ver a los demás que para él el sosiego era una herramienta tan imprescindible como el martillo lo era para su vecino. De hecho,

2. Gurevich, A.: Los orígenes del individualismo europeo. Barcelona, Crítica, 1997.

3. En los últimos tiempos, la historiografía europea ha centrado la atención en estas cuestiones referentes a la cultura material aplicada a los entornos domésticos, así como a la especialización de los espacios habitables y a la correspondiente domesticidad. No podemos olvidarnos aquí de algunos escritos ya clásicos, como el de Ariès, P. y Duby, G. (dir.): Historia de la vida privada. 3. Del Renacimiento a la Ilustración. Madrid, Taurus, 2001; o Braudel, F.: Civilización material, economía y capitalismo, siglos XV-XVIII. Tomo 1. Las estructuras de lo cotidiano: lo posible y lo imposible. Madrid, Alianza, 1984. En cuanto a otras publicaciones de contenido general, son igualmente recomendables Pounds, N. J. G.: La vida cotidiana: Historia de la cultura material. Barcelona, Crítica, 1999; y SARTI, R.: Vida en familia. Casa, comida y vestido en la Europa Moderna. Barcelona, Crítica, 2002. Y en lo que se refiere a las investigaciones sobre localizaciones más específicas de Italia, Francia, o Portugal, pueden consultarse Ago, R.: Il gusto delle cose. Una storia degli oggetti nella Roma del Seicento. Roma, Donzelli Editore, 2006; Pardailhé-Galabrun, A.: La naissance de l'intime. 3000 foyers parisiens, XVIIXVIII siècles. París, Presses Universitaires de France, 1988; Matтoso, J. (dir.): História da Vida Privada em Portugal. Lisboa, Círculo de Leitores y Temas e Debates, 2011; García FernánDez, M. y Dos Guimaraes SÁ, I. (dir.): Portas adentro. Comer, vestir e habitar na Peninsula Ibérica (ss. XVI-XIX). Salamanca, Universidade de Coimbra, Universidad de Valladolid, 2010. Por último, y más en relación con España, resultan de obligada consulta, Blasco EsQuivias, B. (dir.): La casa. Evolución del espacio doméstico en España. Volumen 1. Edad Moderna. Madrid, Ediciones El Viso, 2006; Franco Rubio, G.: «La vivienda en el Antiguo Régimen: de espacio habitable a espacio social», Chronica Nova, 35, 2009, pp. 63-103; y García Fernández, M. (dir.): Cultura material y vida cotidiana moderna: escenarios. Madrid, Sílex, 2013. 
si realmente tenía pensado deshacerse del carpintero de esa manera tan tajante era porque en su fuero interno, el silencio era un elemento propio que le servía para llevar a cabo su profesión y para configurarle además como un individuo de una idiosincrasia muy concreta.

Este caso, pues, nos ayuda a ilustrar el que a continuación va a ser el tema principal de nuestro trabajo. Podría afirmarse que las protestas de Andrés de Serán no fueron sino el reflejo de una pauta concreta de pensamiento, iniciada con seguridad tiempo atrás, y desarrollada a través de los años hasta ser completamente asumida por cierta clase de personas. Lo que aquí trataremos, por tanto, es ofrecer un análisis de estos estudios - de esta clase de espacios físicos- entendiéndolos como unos entornos ciertamente tipificados que fueron pensados para la lectura y la individualidad masculinas, $\mathrm{y}$ que a la vez sirvieron a sus propietarios como focos de exhibición y representatividad social dentro de la vivienda. La investigación, que atravesará la era del Barroco y de la Ilustración, se centrará en la ciudad de Zaragoza, y recurrirá a un tratamiento eminentemente cualitativo de las fuentes empleadas. De hecho, la documentación primaria va a pesar mucho aquí; hemos apostado por una percepción muy minuciosa de la realidad material urbana. Las fuentes notariales han sido el objetivo principal en este sentido, y más concretamente los inventarios de bienes muebles, documentación privilegiada como se sabe y como se suele recordar para el estudio de estos temas ${ }^{4}$. Son casi 700 los inventarios rescatados del Archivo Histórico de Protocolos Notariales de Zaragoza (AHPNZ), procedentes todos ellos de diferentes miembros del entramado socio-profesional de la capital aragonesa de entre los años 1600 y 1800. Las páginas

4. Probablemente no hay ninguna otra fuente que aporte información tan completa sobre la cultura material; con todo, lejos de constituirse como escritos documentales perfectos, el uso de estos recuentos implica por parte del investigador el conocimiento de una serie de problemáticas importantes, como son la propia irregularidad del contenido -que varía en volumen o calidad en función de los notarios, de las épocas o de los lugares-; la escasa representatividad social que refleja -pues cuantitativamente, suelen aparecer muchos más inventarios de individuos «ricos» que de «pobres», cuando los «pobres» eran en número muy superiores a los «ricos»-; o la propia omisión de información, en unas ocasiones porque ciertos objetos de la casa ya habían desaparecido de ella para cuando el notario llegaba, y en otras porque el escaso valor material de ciertos elementos implicaba la exclusión de los mismos a la hora de hacer la lista -ya que la intencionalidad prioritaria del inventario respondía por lo general a los intereses económicos de la familia contratante-. Sobre esta cuestión, consultar Sobrado Correa, H.: «Los inventarios post-mortem como fuente privilegiada para el estudio de la Historia de la Cultura Material en la Edad Moderna», Hispania, LXIII/3: 215, 2003, pp. 825-861; o Baulant, M.: «Typologie des inventaires après décès», en Van Der Woude, A. D. y Schuurman, A. (Eds.): Probate inventoires. A new source for the bistorical study of wealth, material culture and agricultural development. Utrecht, HES, 1980, pp. 33-42.

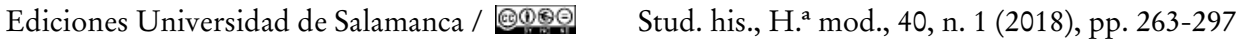


que siguen se encargarán de describir en relación con ello tanto la apariencia y la significación, como la implicación cultural derivada de estos característicos lugares.

\section{LA FISIONOMÍA DEL ESTUdio: LOCALIZACIÓN, ASPECTO EXTERNO E INTEN- CIONALIDAD}

A inicios del siglo XVII ya estaban plenamente establecidas la estructura y composición internas de estas estancias dentro de las casas. Por lo general, los notarios y escribanos, los médicos y cirujanos, los infanzones y ciudadanos, los inquisidores y los religiosos, todos los que requerían de una formación intelectual para desempeñar sus labores profesionales en definitiva, contaban con un estudio dentro de su hogar ${ }^{5}$. Además, y tal y como ocurría en el caso de Andrés de Serán, los estudios solían llevarse a las partes más tranquilas de la casa, lejos de cocinas, bodegas y gallineros o de salones y piezas sociales. A partir de una escalera que arrancaba del patio, los entresuelos de la casa-donde nunca se realizaban las sucias labores cotidianas ni se recibían las constantes visitas o agasajos de ningún tipo- estaban destinados a acoger estas habitaciones de clara orientación individual masculina. Y si bien un análisis morfológico detallado de estas estancias nos llevará a encontrar significativas diferencias respecto a los famosos modelos iconográficos que podríamos observar a través de las representaciones de Antonello da Messina, de Domenico Ghirlandaio, de Cranach o de Durero cuando retrataban a San Jerónimo escribiendo la Vulgata en su hábitat predilecto, lo cierto es que al margen de los consabidos revestimientos estéticos propios del Barroco, aquello que finalmente se iba buscando siempre era la tranquilidad necesaria para la reflexión y el deleite espiritual.

La propia definición escrita por Sebastián de Covarrubias nos adelanta automáticamente y de forma muy clara la esencia ideológica asociada a los estudios del siglo xvir. Por una parte, el lexicógrafo describe el estudio como «el aposento

5. Sobre los estudios zaragozanos, es preciso citar el trabajo de Abad Zardoya, C.: «Donde el arte debe sujetarse a la necesidad. Intendencia doméstica, sociabilidad y apartamentos masculinos en los entresuelos del siglo xviII», en Franco Rubio, G.: La vida de cada día. Rituales, costumbres y rutinas cotidianas en la España moderna. Madrid, Almudayna, 2012, pp. 113-134; y también el de Gómez URDáñEz, C.: «Entre erudición y naturaleza, arquitectura. La casa de Juan Vicencio Lastanosa», en VV. AA.: Vicencio Juan de Lastanosa (1607-1681). La pasión de saber. Huesca, Instituto de Estudios Altoaragoneses, 2007, pp. 59-67. Asimismo, puede resultar de utilidad, Postigo VIDAL, J.: «El estudio como espacio para la intimidad, la intelectualidad y la masculinidad en Zaragoza durante la Edad Moderna», en SERrano Martín, E. (CoORd.): De la tierra al cielo. Lineas recientes de investigación en Historia Moderna. Zaragoza, Institución «Fernando el Católico», 2013, pp. 1067-1082. 
donde el estudiante o el letrado tiene su librería y donde estudia», un entorno básicamente individual por tanto; por otra, entiende que es igualmente la habitación donde los profesionales liberales «negocian [...] dexando el resto de la casa a su familia». El repertorio material hallado en cada uno de estos estudios ineludiblemente irá asociado, así pues, a alguna de estas apreciaciones: a la individualidad del estudioso, a la sociabilidad del negociante, o a la masculinidad y privacidad del cabeza de familia.

En el año 1600 murió el notario Joan Valiente en su casa de la parroquia de San Felipe dejando intacto un estudio que reunía todos los valores simbólicos ligados a estas estancias durante la última parte del siglo xvi ${ }^{6}$. Sobre un tablero de trabajo con sobremesa verde había una pequeña arquimesa, una escribanía, un reloj de arena, un crucifijo de madera, una escobilla, un compás, una campanilla y un cuchillo «de cortar plumas»; elementos todos indispensables para ejercer la labor del propietario, y que estaban acompañados del correspondiente «banquillo de asentarse con sus pies torneados» ubicado junto a la mesa. La presencia de algunos otros útiles sugiere además que esta pieza era frecuentada por Joan con bastante asiduidad, y que era entendida no solo como un lugar de trabajo, sino también como una estancia en la que poder aislarse ocasionalmente del resto de su familia. Al menos eso parece indicar la existencia de una sencilla cama dotada de dos colchones, sábana, almohada y manta verde, de la vestimenta del notario al completo que había dentro de un gran arcón, o de un espejo de cuerpo entero frente al cual posiblemente este hombre se cambiaría antes de salir a la calle. Para acabar, y desterrando todo hálito de hermetismo de la habitación aún a pesar de lo dicho ahora, el estudio de Joan Valiente estaba igualmente preparado para recibir visitas relacionadas con su ocupación: había varias sillas y bastantes elementos decorativos colgando de las paredes; destacaban entre ellos un par de piezas grandes de guadamecí y un lienzo «de la Visitación».

El estudio de Joan Valiente no era para nada excepcional. Todos los hombres de su categoría a lo largo de los siglos XviI y xvin trataron de conseguir habitaciones personales en las que poder «realizarse» de una manera muy concreta, y para ello recurrieron al uso de determinados objetos de consumo que contribuían a hacer efectiva tal pretensión y a proyectarla convenientemente a los demás. Como ocurre siempre, que unos estudios diesen muestras de ese utilitarismo sobrio de corte dureriano y otros en cambio pareciesen estar intentando emular

6. Archivo Histórico de Protocolos Notariales de Zaragoza [en adelante AHPNZ], Martín Martínez de Insausti, 1600, ff. 234 v.- 239 v. 
los famosos studiolos italianos ${ }^{7}$ o las asombrosas wunderkammern nórdicas ${ }^{8}$, es una muestra clara de la relativa libertad personal que podía haber para elegir la forma de darse a conocer ante los demás, a pesar del potente anquilosamiento material al que todavía estaba sometida esta sociedad. Y así como muchas otras habitaciones de la época carecían entonces de una personalidad definida de la que pudiesen hacer gala en todo momento, los estudios eran sin embargo lugares con un perfil muy característico, tan reconocibles por su ubicación y mobiliario como lo eran la cocina, el patio o la bodega. La gran mesa de trabajo con cajones y escribanía, los anteojos, el reloj, la papelera repleta de documentos y ligarzas de papeles, los anaqueles y estanterías con libros, las pinturas religiosas y profanas mezcladas con fingido desorden, los pisapapeles de materiales exóticos con forma de pirámide o de esfera..., esos eran quizás los vestigios materiales que cualquier persona podría esperar encontrar en estas piezas hipotéticamente destinadas a la lectura y la escritura. Naturalmente, esta versión estándar del estudio, si bien no era compartida unánimemente por aquellos intelectuales y profesionales liberales del momento que decidían construir esta clase de habitaciones en sus casas, sí que persistió de forma invicta a través de la totalidad del tiempo que nos ocupa.

Como era de esperar, los estudios relacionados con mayor frecuencia con la tipología más simple y provechosa de todas eran los pertenecientes a los individuos que realmente los necesitaban. Unos pocos años después de la muerte del notario Joan Valiente, en 1611, otro compañero de la profesión llamado Pedro

7. Sobre los precedentes italianos, son interesantes Campbell, S. J.: The Cabinet of Eros. Reinassance Mythological Painting and the Studiolo of Isabella d'Este. New Haven y Londres, Yale University Press, 2004; Currie, E.: «The Study: Business and Pleasure», en Currie, E.: Inside the Renaissance House. Londres, V\&A, 2010, pp. 69-94; FranceschI, F.: «Business Activities», en Ajamar-Wollheim, M. y Dennis, F. (eds.): At home in Renaissance Italy. Londres, V\&A, 2006, pp. 166-172; Kaufmann, T.: The Mastery of Nature: Aspects of Art, Science and Humanism in the Renaissance. Princeton, Princeton University Press, 1993; y Thornton, D.: The Scholar in his Study. Ownership and Experience in Renaissance Italy. New Haven y Londres, Yale University Press, 1997.

8. A día de hoy todavía es una relevante obra de referencia la de Schlosser, J. von: Las cámaras artísticas y maravillosas del Renacimiento tardío. Una contribución a la bistoria del coleccionismo. Madrid, Akal, 1988. También son destacables Morán Turina, J. M. y CHECA, F.: El coleccionismo en España: de la cámara de maravillas a la galería de pinturas. Madrid, Cátedra, 1985; o CANO DE GARDOQui, J. L.: Tesoros y colecciones. Orígenes y evolución del coleccionismo artístico. Valladolid, Universidad de Valladolid, 2001. Y de un modo más global, Mauriès, P: Cabinets of Curiosities, Nueva York, Thames and Hudson, 2002; Impey, O. y MacGregor, A.: The Origins of Museums: The Cabinet of Curiosities in Sixteenth-and Seventeenth-Century Europe. Oxford, Oxford University Press, 1985; Lugli, A.: Wunderkammer: la stanza della meraviglia. Turín, Allemandi, 1997; y de la misma, Naturalia et mirabilia: les cabinets de curiosites en Europe. París, Adam Biro, 1998. 
Jerónimo Pasamar fallecía en su casa de la calle de los Agujeros9. El notario Pasamar era más afortunado que el abogado Andrés de Serán y probablemente nunca tuvo que pleitearse con nadie por motivos de contaminación acústica, pues vivía entre las casas de dos «licenciados», Juan Bela y Pedro de Asolo. Su estudio, además, era la viva imagen del espacio dedicado a la concentración intelectual y a la contemplación católica; los objetos que lo poblaban exhalaban una sencillez y una devoción muy claras. Protagonizada principalmente por la gran mesa de pino con cajones y tapete de paño azul, el resto de la estancia estaba amueblada únicamente por lo indispensable: una arquimesa, un par de bancos sencillos, tres sillas y un candelero «de tres mecheros de estudio». En cuanto a la decoración, las pinturas representando a la Virgen del Pilar, al Ecce Homo, o también el crucifijo de madera, expresaban una religiosidad discreta muy al gusto de los moralistas del momento.

El estudio modélico de Pasamar, tan ventajoso como insulso, fue adoptado una y otra vez sin sufrir variaciones significativas. En 1614, Diego López (de quien no se nos especifica la profesión) también tenía su «tablero de pino largo con su cubierta verde», un par de sillas de nogal, una arquimesa en la que se guardaban unos rosarios, algo de dinero, los «ubillos de yllo de atar cartas» o la caja de los anteojos, y por último, un par de pinturas de San Juan y la Magdalena ${ }^{10}$. Y en 1631, el estudio del regente de la Real Cancillería del Reino Juan Francisco de Salazar, que se hallaba en su casa del Coso, estaba perfectamente preparado para poder conservar ordenadamente enormes cantidades de documentación manuscrita $^{11}$. Destacable era un gran armario «donde están los libros del concejo» que al abrirlo mostraba dos calajes y varias baldas de madera en las que se clasificaban los volúmenes; pero no menos interesantes resultaban el conjunto de arquillas y cofres numerados (se cita un «cofre de pelo de buey cerrado con un retulo borrado donde dize $\mathrm{n}^{\circ} 8 »$ ) en los cuales se habían introducido todos los papeles amontonados y cuidadosamente organizados por temas, recurriendo para ello a cordones anudados, a envoltorios de cartón, a cuadernos con títulos específicos o a sellos de cera.

La impresión que nos sugieren estos últimos estudios comentados es la de un rigor muy fuerte infligido por cada propietario, una pretensión quizás perfectamente definida y encaminada a cubrir ciertas necesidades asociadas al trabajo personal. Sin embargo, estos requerimientos comunes a muchos hombres no

9. AHPNZ, Juan Domingo Navarro, 1611, ff. 16 r.- 26 r. La calle de los Agujeros estaba en la parroquia de el Pilar.

10. AHPNZ, Domingo Montaner, 1614, ff. 619 v.- 632 r.

11. AHPNZ, Juan Jerónimo Navarro, 1631, ff. 3.571 v.- 3.575 r. 
siempre podían llegar a ser satisfechos acogiéndose a espacios tan acotados como los descritos o recurriendo a repertorios de objetos tan señalados y escogidos. A veces los individuos decidían acondicionar varias habitaciones de la casa organizadas de forma conjunta para establecer allí sus «estudios», o lo que es lo mismo, para recogerse individualmente en un lugar propio al margen del resto de los miembros familiares. Tal y como ocurría con el modelo estándar, también en esta clase de ejemplos se escogía la parte de los entresuelos para localizar los lugares donde expresar libremente la masculinidad; la diferencia básica estaba en que ahora se reservaban para tales fines todas las habitaciones que consecutivamente se encontraban en esa parte de la casa (a veces eran dos, a veces tres). Por lo tanto la significación final iba igualmente a resultar distinta si contemplamos estas actitudes desde un plano simbólico: con el modelo estándar se buscaba hallar un entorno propicio para el trabajo intelectual; con la acumulación de espacios para el pater familias se perseguía la construcción de un auténtico medio ambiente a la medida del hombre donde poder auto-representarse o incluso habitar indefinidamente al margen del resto de personas de la casa.

Ya en 1603 la vivienda del notario Bartolomé Malo en la calle de Santiago mostraba esta categoría específica distinguiendo entre un «estudio primero» y un «estudio segundo» ${ }^{12}$. El primero se caracterizaba por su austeridad, únicamente había en él un tablero de pino y una pintura de la Magdalena; el segundo en cambio parecía haber sido ideado para impresionar a quien fuese a visitarlo. El tablero «con tres armarios», el escritorio y la arquimesa de taracea «con dos armarios abajo» y el conjunto de cinco sillas y banco de nogal con respaldo, estaban acompañados aquí de un arcón grande en el que se guardaban las prendas de vestir del notario y de un grupo de siete pinturas; tres de estas pinturas mostraban la historia narrada en la parábola del hijo pródigo.

Más evidentes son todavía los casos en los que las habitaciones que formaban los entresuelos de la vivienda estaban amuebladas con camas y otros elementos relativos al aseo personal masculino, por ejemplo, pues es entonces cuando se hace patente que los anhelos de intimidad trascendían a la propia necesidad que traía el trabajo. En ocasiones de este tipo, bastante frecuentes desde inicios del siglo XVII, resulta de hecho evidente que la soledad no era entendida -al menos no de manera monolítica- como un recurso estrictamente utilitario asociado a la labor de los letrados, sino más bien como una forma de sustraerse ocasionalmente de los ritmos de la convivencia familiar. El notario que entró en marzo de 1620 en una casa de la plaza del Carmen que hasta entonces había sido habitada por

12. AHPNZ, Francisco Martín Antich Bages, 1603, ff. 785 v.- 799 v. 
el ciudadano Juan de Tiermas, tuvo muy claro al acceder al entresuelo de que se encontraba en los «estudios» de la vivienda, aún cuando en ninguna de sus dos habitaciones observó mesas de escritorio, tinteros, papeles o libros ${ }^{13}$. El hecho que le llevó a definir así esa parte de la casa fue la sencilla convicción de que se hallaba en un espacio pensado por y para el hombre.

Al subir ese primer tramo de escaleras, lo que podía observarse al cruzar el umbral de la puerta era precisamente un cúmulo de objetos que poco tenían que ver con aquella versión tradicional del estudio que los ambientes religiosos medievales habían contribuido a conformar. Una silla de tijera, una arquimesa de Alemania, una escribanía «grande pintada» y un par de espejos -uno de ellos roto-, era todo lo que el visitante encontraría allí en relación con la visión más tradicional que se tenía de esas estancias. Dentro de los cajones de la arquimesa se escondían siete «lienços de narices de Olanda», unos guantes, unos cuchillos con sus vainas y un par de «bonetillos de tafetán colchados»; en torno a la escribanía se amontonaban unas cuantas piezas de plata, como eran candeleros, bacinillas, pebeteros, fuentes, jarros, cucharas, tazas e incluso un salero «de dos pieças con quatro pilarillos»; y de las paredes pendían un sinfín de cuadros -más de treintaque tenían como temas predilectos retratos de santos o de apóstoles y distintas escenas de género (se anotaron «un quadro de una gitana», otro "de un oso» y dos «de todo genería»). La última habitación de los entresuelos, apuntada en el inventario como "primero aposento del estudio», estaba por su parte articulada directamente a partir de una cama de medios pilares pintada de dorado que tenía cortinas de tafetán rojo, pajizo y azul, un cielo de paramento de damasco, una almohada de terciopelo negro y un total de cuarenta y siete tiras de catalufas verdes y doradas cosidas a las colgaduras. Este espectacular mueble iba a su vez acompañado de dos bancos acolchados, de varias armas expuestas (un arcabuz, una ballesta y un par de pedreñales) y de dieciséis paños de ras que seguramente cubrirían la totalidad del espacio existente.

Las dos habitaciones de ese entresuelo eran seguramente para Juan de Tiermas una especie de casa propia dentro del hogar familiar. En principio nadie más podría entrar libremente en esos aposentos reservados específicamente al cabeza de familia; su mujer, sus hijos, los criados, todos tendrían vetado el acceso a los estudios, a no ser que el propio Juan accediese a darles permiso una vez que estuviese él mismo ya dentro. Y no es un caso aislado el de este ciudadano. Desde los primeros años del siglo XviI ya se aprecia como una verdadera tendencia ese comportamiento característico. En 1618 el estudio de Juan del Campo exhibía de la misma forma

13. AHPNZ, Pedro J. Martínez de Aztarbe, 1620, ff. 428 r.- 439 v. 
una imponente cama de aparato con escalerilla y cuatro pilares dorados acabados en manzanas que estaba rodeada de fuentes, tazas y jarros de plata, por alfombras de colores (una de ellas «grande de leones»), y por una serie de paños de ras que plasmaban «la historia del Rey Nabucodonosor» ${ }^{14}$. Muchos otros testimonios de la época que andan en la misma dirección nos hablan igualmente de un anhelo muy concreto de sustracción física dentro de los dominios familiares, si bien para ello muchas veces se optaba por hacer gala -como en el caso de Juan del Campo-de cierta arrogancia babilónica ${ }^{15}$. Efectivamente, además de la cama, de los trajes, del espejo, del estuche con navaja de afeitar, tijerillas y peine, de la espada, la pistola y de otros objetos relacionados con la expresión individual varonil, no era extraño que apareciesen elementos de ostentación muy significativos que transformaban estas estancias de hipotética intencionalidad privada y reflexiva en verdaderas

14. AHPNZ, Francisco Moles, 1618, ff. 85 r.- 86 r. En el inventario de este estudio también se anotan una mesa de trabajo, un par de bancos, las prendas de vestir del ciudadano, una espada, y algún que otro objeto decorativo, como era el «quadro de San Agustín con una coronilla de tafetán pagizo y una varetilla de plata».

15. La historia del lujo y del consumo han adquirido asimismo una gran importancia últimamente, sobre todo a partir de la publicación de trabajos como Brewer, J. y PORTER, R. (eds.): Consumption and the World of Goods. Londres-Nueva York, Routledge, 1993; SchuURman, A. y Walsh, L. (eds.): Material culture: Consumption, Life-style, standard of Living, 1500-1900. Eleventh International Economic History Congress, Milán, 1994; BREwer, J. y Bermingham, A.: The consumption of culture, 1600-1800. Image, object and text. Londres, Routledge, 1995; Cornette, J.: «La Révolution des objects. Le París des inventaires après déces (xviIe-Xvine sièclees)", Revue d'Histoire Moderne et Contemporaine, XXXVI, 1989, pp. 476-486; WARODesjardins, F.: La vie quotidienne dans le Vexin au XVIIIe siècle. Dans l'intimité d'une societé rurale (d'après les inventaires après décès de Genainville (1736-1810). Pontoise, Éditions du Valhermeil, 1992; Roche, D.: Histoire des choses banales. Naissance de la société de consommation, XVIIIe-XIXe siècles. París, Fayard, 1997; Welch, E.: De compras en el Renacimiento. Culturas del consumo en Italia, 1400-1600. Valencia, Universitat de València, 2009. Y en lo que respecta a la península Ibérica, recordamos los siguientes trabajos: Yun Casalilla, B. y Torras, J. (dirs.): Consumo, condiciones de vida y comercialización: Cataluña, Castilla, siglos XVII-XIX. Junta de Castilla y León, Consejería de Educación y Cultura, 1999; Yun Casalilla, B.: «Consumo, mercados y sociedades: Sobre la historia económica de la Europa del Antiguo Régimen y la formación de una identidad europea», en Marcos Martín, A. (coord.): Hacer historia desde Simancas. Homenaje a José Luis Rodríguez de Diego. Valladolid, Junta de Castilla y León, 2011; Bartolomé Bartolomé, J. M.: «Niveles de riqueza patrimonial, condiciones de vida y pautas de consumo de las familias de comerciantes y financieros de la ciudad de León (1700-1850)», en Chacón Jiménez, F. y Gómez Carrasco, C. J. (coords.): Familias, recursos bumanos y vida material. Murcia, Servicio de Publicaciones, 2014, pp. 181-199; Bartolomé Bartolomé, J. M.: «Consumos y apariencias externas de las familias de la burguesía leonesa (1700-1850)», Studia Historica. Historia Moderna, 37, 2015, pp. 269-290; así como los trabajos de Máximo García Fernández, de entre los cuales destacamos, García Fernández, M. y Bartolomé Bartolomé, J. M. (dirs.): Apariencias contrastadas, contraste de apariencias. Cultura material y consumos de Antigno Régimen. León, Universidad, 2012.

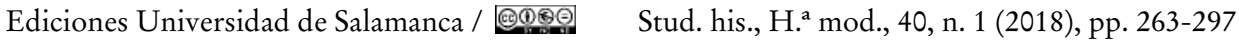


plataformas de proyección social. A pesar de la obvia voluntad que apreciamos a través los estudios por encontrar un entorno único y propio, no parece que estemos todavía ante casos comparables al de la clausura de aquella mujer que a mediados del siglo xviII continuaba dando muestras fastuosas de prodigalidad aún cuando era plenamente consciente de que no tenía a nadie a quien dirigirlas.

Detrás del estudio cargado de ricos muebles y de objetos de ostentación había con total seguridad intenciones socializadoras. No debemos olvidar de hecho que entre sus funciones básicas estaba la de servir como espacio de reunión para negocios -espacio físico de conjunción entre iguales por tanto-, de forma que todos sus objetos, si bien debían cumplir con los cometidos laborales y personales del individuo, también habían de resultar asimismo decorosos y correspondientes al estatus social de su propietario. Es innegable que durante los últimos años del siglo xvi y los primeros del xvir hubo muchos hombres en la ciudad que al igual que el reivindicador Andrés de Serán entendieron como básicos determinados fundamentos de privacidad y llegaron al punto de defenderlos como si se tratara de un derecho inviolable. Pero fallaríamos al suponer que ya entonces imperaba el pensamiento manifestado por Javier de Maistre a finales de la Ilustración cuando se preguntaba si podría existir en el mundo un hombre tan desgraciado que careciese de un refugio donde poder retirarse en soledad y donde poder ocultarse de los demás ${ }^{16}$. La privacidad del estudio propia de las culturas del Renacimiento y del Barroco más temprano era sencillamente una de las señas de identidad de un arquetipo de la masculinidad muy concreto. No era ni mucho menos algo de lo que pudiese disfrutar cualquiera; era un signo más de distinción. Es así como nos encontramos con modelos de estudio que efectivamente trataban de resultar «útiles» (entendiendo como útil todo aquello que nos sugieren las representaciones citadas de San Jerónimo), y con modelos que manifestaban la preocupación de sus propietarios por codificar de una manera visual determinados valores ligados a las ideas de intelectualidad y liberalidad.

En muchas de esas camas doradas con paramentos de damasco carmesí figuraban estratégicamente colocados escudos de Armas que debían asociar simbólicamente al individuo con un tronco familiar de gran estimación. Lo mismo ocurría con los retratos (género pictórico al que la mayoría no tenía acceso) o con las piezas de plata labrada que se exponían junto a las arquimesas taraceadas, a las alfombras turcas o a los enormes paños de ras. En cuanto a los cuadros, estos eran sin lugar a dudas el elemento decorativo más recurrente de los estudios, sobre todo cuando los

16. «¿Es posible, en efecto, ser tan desgraciado, hallarse tan abandonado, que no se tenga un refugio donde poder retirarse y ocultarse a las gentes?». MAIsTRE, J.: Viaje alrededor de mi cuarto. Buenos Aires, Espasa-Calpe, 1950, p. 7. 
poseedores tenían la intención de proyectar en la mente de los posibles invitados imágenes simbólicas señaladas. Quien accediese a los entresuelos de algún sujeto adinerado con pretensiones intelectuales, probablemente quedaría asombrado precisamente por la inmensa cantidad de figuras antropomorfas que percibiría, por la acumulación de escenas que conseguiría -o no-identificar. Las pinturas se amontonarían por las paredes formando conjuntos heterogéneos de historias y de formas particulares; no habría huecos vacíos, y los espacios resultantes entre las ventanas o entre el marco superior de la puerta y el techo se rellenarían igualmente de imágenes cargadas de simbolismo que únicamente serían descifrables para el observador mejor instruido. A las acostumbradas figuraciones de vírgenes y santos se sumaban ahora retratos de personajes ilustres, de apóstoles, de padres de la Iglesia, de papas, de emperadores antiguos, o de reyes del pasado y del presente. Frecuentes eran también las escenas bíblicas que narraban pasajes especialmente conocidos del Antiguo Testamento o de la vida y Pasión de Jesucristo, las cuales podían combinarse igualmente con plasmaciones de determinados mitos provenientes del mundo grecolatino que habían calado hondo en la cultura de elites contrarreformista.

Estas composiciones, por otra parte, en ocasiones resultarían ser un pretexto para mostrar al espectador asombrosos paisajes cargados de bucolismo y salpicados de grandiosas ruinas de civilizaciones pretéritas. De hecho, muy recurrentes eran también los paisajes en estos estudios -o pintura «de países», como se apunta en los inventarios-, así como las escenas de batallas, las «marinas» o también los mapas. La naturaleza muerta, finalmente, tenía asimismo su protagonismo en el espacio masculino de los entresuelos; representaciones de bodegones clásicos, y especialmente los que contenían piezas de fruta -«fruteros»- o flores-«floreros»-, eran los repetidos con mayor asiduidad. La pieza de la vivienda más claramente destinada al desarrollo de la intelectualidad era como puede observarse la que acababa dando signos de una especial predilección por los temas decorativos cultos y profanos. Lo vemos constantemente: en 1603, el médico Juan Francisco Pallarés tenía en su estudio, además de las acostumbradas imágenes de la Virgen, del Ecce Homo, de la Magdalena, o de Santa Isabel de Portugal, una pintura «de un Pícaro» ${ }^{17}$. En 1611, el notario Diego Casales había conseguido estructurar el perfecto estudio con pretensiones «sociales», más pendiente de las miradas externas que de otra cosa; la imponente colección de piezas de plata que incluía tazas, bernegales, pilas, portaderas, cucharas o saleros, se combinaba aquí con elementos exclusivos como podían ser lujosos relicarios, cocos guarnecidos de plata, platos de Talavera, o

17. AHPNZ, Juan Martín Sánchez del Castellar, 1603, ff. 1.546 v.- 1.560 r. 
también con los elementos propios de la profesión de su propietario (ligarzas de cartas, protocolos de notario, o libros de cuentas del oficio).

La decoración de la estancia de Diego Casales se centraba en la exposición de algunos «fruteros» superpuestos a auténticos jarros con flores silvestres, en la muestra de pinturas devotas con reliquias incrustadas en los marcos, y también en la colección de un grupo de doce lienzos «de sivilas» ${ }^{18}$. Unos cuantos años después, en 1621, el infanzón Antonio de Ejea mostraba en su estudio hasta «16 quadros de emperadores» ${ }^{19}$, y en 1652 el infanzón ciudadano Bernardo Arrain poseía -además de una pintura de San Jerónimo y de una hechura pequeña de Cristo crucificado en oro- unos cuantos cuadros «de hombres insignes de Alemania» ${ }^{20}$. Mucho más espectacular era en cambio el repertorio de pinturas del infanzón y militar de la Inquisición Felipe Tomás Garro, que falleció ese mismo año de 1652 dejando en su estudio «siete quadros grandes de los filósofos con sus marcos sin dorar», «4 floreros y dos quadricos de sobrequenta y ventana de pays», «12 angelotes dorados de cartón», «dos fruteros de cartón», «12 sebillas» [sibilas], «cinco quadros grandes de las diosas», «un bodegón», «quatro dotores de la yglesia», «otro quadro de la diosa Benus», «12 quadros de los ynfantes de Lara», "otro quadro de un sátiro con una muger desnuda», "otro quadro de la oración del guerto con su marco dorado», «tres payses con sus marcos», «un quadro de una leona», «otro quadro de Felipe terçero», o incluso varios paños de raz con «figuras» (uno de ellos con la representación de San Juan) ${ }^{21}$.

\section{ESPACIOS PARA LA PROYECCIÓN SIMBÓLICA}

Estas explosiones de erudición plástica no solo no perdieron vigencia con el paso del tiempo, sino que muy al contrario consiguieron potenciar su presencia con una intensidad creciente e ininterrumpida. A finales del siglo Xvir, y más aún durante todo el siglo xviII, el hecho de poseer un estudio dentro del hogar significaba prácticamente el ser propietario de una especie de sala de exposiciones

18. AHPNZ, Pedro J. Martínez de Aztarbe, 1611, ff. 881 r.- 891 r. Los retratos de sibilas fueron muy frecuentes en los estudios zaragozanos durante el siglo xvII. Generalmente se acumulaban en grupos de diez o de doce pinturas, aludiendo precisamente a los famosos personajes mitológicos pertenecientes al culto griego y romano que principalmente estaban relacionados con ciertos mensajes proféticos. Posiblemente estos conjuntos pictóricos se constituirían además como una interesante oportunidad para adornar las paredes de la estancia masculina con imágenes de bellas mujeres aisladas en parajes remotos.

19. AHPNZ, Juan Moles, 1621, ff. 241 r.- 250 r.

20. AHPNZ, Juan Isidoro Andrés, 1652, ff. 1.806 r.- 1.855 v.

21. AHPNZ, Lorenzo Villanueva, 1652, ff. 672 v.- 675 v. 
donde poder hacer gala de los altos niveles adquisitivos y culturales del individuo ${ }^{22}$. Partiendo de la función social que estas piezas habían tenido ya desde los inicios de su propagación, los entresuelos acabaron por incluir entre sus repertorios de muebles exageradas cantidades de sillas, mesas, bufetes, arquimesas, y por supuesto, también de espejos, cortinajes, pinturas y de otros muchos elementos decorativos que contribuyeron a transformar completamente y de forma definitiva aquellas celdas primitivas sobre las que se había edificado la idea del estudio para el letrado. No es que el tipo de estudio estándar fuese quedando con el transcurrir de los años obsoleto -de hecho todavía se siguió recurriendo a él en muchas ocasiones-, sino que la inclusión de determinados objetos que podríamos calificar como superfluos se fue haciendo frecuente independientemente de la utilidad práctica que fuese a tener la habitación.

Esta tendencia debemos situarla dentro de un gran proceso cultural al que la sociedad en general quedó volcada y que se caracterizó principalmente por la adquisición de mayores cantidades de objetos consumibles como recurso fundamental para seguir manteniendo las distancias estéticas entre los estratos ${ }^{23}$. Que el infanzón ciudadano Juan José Calvete ${ }^{24}$ hubiese acondicionado hasta su muerte en 1676 el estudio de su vivienda orientado hacia la plaza de la Seo con veintitrés sillas, con una cama «entera dorada con las armas de su cassa y paramento de damasco carmessí», con siete espejos grandes de molduras talladas en ébano, con varios bufetes, escritorios y arquimesas de ébano y marfil, con dos cortinas «con sus zenefas de cordellate colorado guarnecidas de galón de plata falzzo», o con doce pinturas de evangelistas y profetas, no nos viene sino a confirmar la idea de que la carrera material y simbólica que la sociedad zaragozana emprendió durante el siglo xvir pudo llegar a condicionar algunas de las prácticas de individualidad que lentamente se habían ido introduciendo ya desde fines de la Edad Media.

22. Sobre la relación entre el poseedor y su colección, son interesantes MUENSTERBERGER, W.: Collecting: an unruly passion. Psychological perspectives. Nueva York-Londres, Harcourt Brace \& Co., 1995; Blom, P.: To have and to hold. An intimate history of collectors and collecting. Nueva York, Overlook Press, 2003; Elsner, J. y Cardinal, R.: The Cultures of Collecting. Cambridge, Harvard University Press, 1994; o también, Bleichmar, D. y Mancall, P. C.: Collecting across cultures. Material exchanges in the Early Modern Atlantic World. Philadelphia, University of Pennsylvania Press, 2011.

23. Esta es una hipótesis que hemos defendido en otros lugares y a través de una tesis doctoral que se publicó recientemente: Postigo VIDAL, J.: La vida fragmentada. Experiencias $y$ tensiones cotidianas en Zaragoza (siglos XVII y XVIII). Zaragoza, Institución «Fernando el Católico», 2015.

24. AHPNZ, Diego Miguel Andrés, 1676, ff. 569 r.- 580 r. 
En principio resulta innegable que si el sentido de la privacidad filtrado en los espacios habitables a través de los estudios ya era en sus inicios concebido como un signo de distinción, conforme más espectros sociales se viesen capaces de acceder a nuevas y deseables manifestaciones de civilidad, la apariencia de estas habitaciones iría evolucionando y refinándose en dirección ascendente. Conviene tener en cuenta, así pues, que a diferencia de lo que ocurría todavía durante las primeras décadas del siglo XvII, cuando un carpintero podía llegar a sentirse extrañado por las molestias expresadas por su vecino debido a los -leves- ruidos que al parecer le llegaban desde el taller, hacia la última parte del siglo xviı algunos artesanos de la ciudad ya participaban activamente en este proceso evolutivo de la individualidad cuando decidían incluir también estudios en sus casas. En un contexto así empieza a cobrar mayor lógica el pensamiento de Javier de Maistre, pues la compartimentación de los espacios, la búsqueda de lugares propios y restringidos, ya podía estar dejando de ser un factor estrictamente identitario. Hasta su fallecimiento en 1771, el cerero y confitero Francisco Monzón había poseído un estudio en los entresuelos de su vivienda de la calle de la Sombrerería, lo cual hubiese sido impensable tiempo atrás. Aparentemente no había nada que diferenciase este estudio del de cualquier otro profesional liberal de la época, tenía su mesa con cajones, cinco sillas y bastantes fajos de documentos notariales concernientes a la familia del difunto. Sí que se incluían algunos otros elementos propios de la profesión de Francisco -como eran una arca con confituras, un tablero de trabajo, un par de tornos y varios calderos y ollas- que quizás conferían de una personalidad diferente a una estancia que por definición había estado tradicionalmente orientada a la quietud de la reflexión mental. Por lo demás, en cambio, el estudio del confitero se mantenía en la línea general, ya que incluía las acostumbradas piezas de plata y también algunos relicarios y otras «bugerías» ${ }^{25}$. En la misma época el mantero Francisco Arrieta pudo disfrutar igualmente de estudio propio en su hogar; la diferencia en este caso respecto al anterior estaba en que el mantero contaba con un «estudio alto» y con un «estudio bajo». En el alto había una cama sencilla de bancos y cañizos, diez sillas, una papelera, cuatro mesas y dos taburetes. En el bajo una mesa, cuatro sillas, una arquimesa y un taburete ${ }^{26}$.

Más curioso podrá parecernos sin embargo el caso de José Boira, un carpintero que murió en 1771 y que también poseyó un «retrete llamado estudio» situado justo encima de su taller. Desde luego, si tuviésemos la oportunidad de comparar los requerimientos personales de Juan Sierra, que en 1632 mostraba su absoluta incomprensión hacia la conducta inconformista de su vecino, con los de José

25. AHPNZ, Antonio Bernués, 1771, ff. 618 r.- 639 v.

26. AHPNZ, Juan de Campos Ardanuy, 1770, ff. 449 v.- 469 r. 
Boira, quien dadas las circunstancias que le rodeaban ya consideró preciso tener un estudio en sus entresuelos, apreciaríamos con seguridad un cambio de sensibilidad absoluto entre ambos. Claro que, por otra parte, el estudio de José Boira encontraba su razón de ser precisamente en la satisfacción de unas necesidades que a este hombre le resultarían «reales»; no era poseedor por ello de una extensa biblioteca, de una mesa de escritorio, o de los típicos libros de cuentas y de los papeles repletos de apuntes, el modelo de estudio que le interesaba tener era sin duda otro. Aunque dentro de una papelera se hallaron algunos de los útiles básicos que todo carpintero debía tener, como eran «un estuche pequeño con cinco compases diferentes»o «una escuadria, tres plumas de ierro [y] una lapizera», el estudio de Boira no hubiese podido ser considerado bajo ningún concepto como un espacio de trabajo. En el interior de cada una de las arcas, cajas de madera o arquimesas de la habitación, no se encontraron finalmente sino vestigios destinados al lucimiento personal del carpintero: trajes y joyas básicamente ${ }^{27}$.

La progresiva compartimentación de los espacios de la casa posibilitó la inclusión de estudios con mayor frecuencia, aunque estos muchas veces parecían estar diseñados como vemos para colmar apetitos banales relacionados sobre todo con la moda y la estética. Es muy posible que este comportamiento terminase además por germinar en formas culturales más profundas, al menos eso es lo que aquí defendemos; lo que parece más improbable en cambio es que el simple hecho de que los estudios se extendieran a nuevos sectores sociales ajenos en principio al universo de la cultura de elites, pudiese contribuir significativamente a propagar la necesidad por recurrir a determinadas manifestaciones de intelectualidad entre los trabajadores manuales o entre ciertos individuos del tercer estado.

\section{EsPACIOS PARA LA ESCRITURA}

Intentar determinar con acierto qué personas eran aquellas que se acercaron más a la cultura escrita a lo largo de los siglos xvir y xvinI, eso es algo que se sale de nuestros intereses. No obstante, es necesario que tratemos de esbozar un retrato general de este panorama para poder comprender realmente si la expansión de los estudios pudo estar de alguna manera relacionada con cierto ensanche en el horizonte escritor y lector de la ciudad. La relativa variedad tipológica que caracterizó a esta clase de habitación -y que sugiere como venimos diciendo una correspondiente variedad de usos de la misma- se entenderá quizás algo mejor si rastreamos a través de los inventarios qué personas poseían en sus casas los aparejos necesarios para escribir.

27. AHPNZ, Eustaquio Vidal, 1771, ff. 62 v.- 67 v. 
Los resultados de la tabla elaborada (ver el cuadro al final del artículo) no deben ser leídos como algo definitivo en ningún caso. Sería una temeridad atribuir automáticamente el analfabetismo a un individuo que no poseyese instrumentos para la escritura; de hecho, de hacerlo así tendríamos por analfabetos a muchos hombres que no contaban con tinteros ni escribanías en el momento de la redacción del inventario, pero que evidentemente estaban ampliamente preparados por la profesión o rango social que detentaban para escribir y leer con corrección. Sin embargo, la imagen ofrecida por los datos aquí recopilados puede servirnos para ilustrarnos una tendencia general de la que aparentemente sí que podríamos fiarnos. Y partiendo pues de esta base, vemos que salvo algunas excepciones cuya trascendencia es difícil de calibrar, el conocimiento de la escritura -o al menos su práctica- continuó estando bastante restringido a unos pocos sectores de la población durante todo el periodo que nos ocupa. Naturalmente, sería absurdo que obviásemos aquí los evidentes avances de escolarización que hubo a lo largo de la Ilustración, o el interés mostrado por muchos autores que publicaron incesantemente sencillos manuales por los cuales se aseguraba poder aprender a leer y a escribir de manera casi autónoma ${ }^{28}$. Pero tampoco sería demasiado realista interpretar esa realidad de forma excesiva, es decir, tratar de atribuir destrezas determinadas a una parte de la sociedad que no las requería apremiantemente. De hecho, si atendemos al tono en que están escritos estos manuales de enseñanza caligráfica, comprobaremos que todavía a fines del siglo xviII se tenía un concepto muy «alto» de esta arte liberal, susceptible de seguir marcando distinciones entre la gente por tanto. Cuando en 1798 Torcuato Torío de la Riva y Herrero publicó su Arte de escribir por reglas y con muestras, acabó realizando algunas afirmaciones que se sitúan concretamente en esta línea ideológica:

Arte liberal, según los eruditos, es aquel en que trabaja o se emplea más el entendimiento que la mano, o, lo que es lo mismo, aquel que consiste más en especulativa que en práctica: viene del latino liberalis, que significaba entre los Romanos el que no era, ni había sido siervo; teniéndolas en tanta veneración que eran entre ellos muy poco menos estimadas que las ciencias. Jamás deshonraban á sus profesores como sucedía en las mecánicas ó puramente prácticas, que las egercían los esclavos y la gente más baja é idiota del pueblo, quienes á manera de irracionales empleaban solo las fuerzas corporales en los oficios y manufacturas á que se dedicaban. Tratar ahora sobre a cual de las artes liberales corresponde la de la escritura, es asunto sobre muy prolijo poco interesante. Bástanos saber que

28. Fernández Clemente, E.: Estudios sobre la Ilustración aragonesa. Zaragoza, Institución «Fernando el Católico», 2005. 
es una de ellas, y que está bastantemente unida con la Gramática y Geometría, que son dos de las siete a que todas se redugeron principalmente ${ }^{29}$.

Volviendo de nuevo a la tabla, salta a la vista que los propios objetos que servían para escribir apenas evolucionaron a lo largo de doscientos años. Y es que aquellos puntos en los que Torcuato Torío de la Riva había incidido a fines del siglo xviII, como eran la cuestión de si era preferible aprender a leer y a escribir simultáneamente o no, la forma en que debía ser cortada la pluma, la calidad de la tinta y del papel, la manera de dibujar las letras con estilo... ya fueron igualmente desarrollados por otros autores como Juan de $\mathrm{Icíar}^{30}$ en las primeras décadas del siglo xvi. El ejercicio de escribir, siendo por tanto entendido como un arte merecedor de conocimientos y técnicas precisas y refinadas, mantuvo durante toda la modernidad un mismo repertorio material y gestual que indirectamente reconocía su propia perfección metodológica al concebirse como algo atemporal. A pesar de que siempre se debatió acerca de si era mejor coger la pluma con dos o con tres dedos, lo cierto es que en lo básico el procedimiento quedó establecido pronto para no variar en nada: era conveniente agarrar la péñola con los dedos pulgar e índice haciéndola reposar sobre el corazón y apoyando el resto de la mano sobre el papel; esto hacía que el antebrazo quedase libre y que únicamente fuese el codo el que entrara en contacto con la superficie de la mesa. Sobre esta última, había que tener en cuenta su altura proporcionada en función de la estatura y complexión de la persona, pues ahí radicaba lo más importante de la correcta adecuación de la postura. La línea exterior de la tabla debía corresponder con la parte baja del pecho del escribiente, entendiendo que este había de permanecer en todo momento en una posición erguida para que el brazo pudiese adoptar la forma descrita.

Incuestionablemente se entendió que la mano para escribir era la derecha -lo mismo que la pluma utilizada procedería del ala derecha del ave-, así que la postura de las piernas también se vería condicionada por tal circunstancia. Evitando dejar los pies colgando, se sabía que se trabajaba mejor si el izquierdo quedaba apoyado sobre algún travesaño o tabla que tuviese la mesa y el derecho permanecía mientras tanto naturalmente asentado en el suelo; así el cuerpo se inclinaba un poco hacia la derecha y el brazo de escribir se relajaba algo más. Para que no hubiese proyecciones de sombras sobre el papel, preferiblemente la luz procedería lógicamente del lado izquierdo (cosa que condicionaría la orientación de la habitación dentro

29. Torío de la Riva y Herrero, T.: Arte de escribir por reglas y con muestras. Madrid, Viuda de Joaquín Ibarra, 1798, p. 97.

30. ICÍAR, J.: Arte subtilíssima por la qual se enseña a escrevir perfectamente, Marca tipográfica de Juan de Icíar y Juan de Vingles, 1522 o 1523 (algunos de los textos están fechados en 1550). 
de la casa, o por lo menos la de la mesa dentro de la habitación), y la posición de este soporte, en vez de quedar fijada de forma paralela a la línea de la mesa como podría pensarse, estaría mejor un poco inclinada a la izquierda para que los dedos de la mano libre pudiesen apoyarse sobre la esquina superior de la hoja.

En líneas muy generales así fue el impasible panorama de la escritura durante los siglos XVII y xviII. Unos mismos utensilios utilizados de una misma forma y muy probablemente por las mismas personas. No nos puede resultar entonces extraño que los lugares donde aparecían los tinteros y las escribanías fuesen muchas veces también los mismos en los que se almacenaban y exhibían los libros en la casa, o que algunos de los sujetos que contaban con estos aparejos de escribir fuesen los que poseían asimismo un modelo de estudio claramente monopolizado por la palabra escrita. Los entresuelos pertenecientes al infanzón y causídico de la Real Audiencia del Reino José Antonio Cebrián, donde en 1737 apareció aquel «tablero de estudio con seis cajones, tintero y salvadera» que se refleja en la tabla, estaban precisamente pensados conforme a este modelo descrito ${ }^{31}$. Los estudios de esta casa de la calle del Coso a su paso por la parroquia de San Miguel se articulaban a través de dos habitaciones consecutivas; en la primera se guardaban la mesa con los utensilios para escribir, así como un total de ocho sillas, dos taburetes, una arquimesa con piezas de plata dentro y hasta diez pinturas «de imágenes» con marcos negros; en la segunda era donde aparecieron los dos estantes con celosías en los que se guardaban los libros. La biblioteca compartía finalmente espacio en la pieza con una cama, con una arca llena de papeles, con cuatro sillas y con seis pinturas pequeñas.

Que los estudios se expandiesen y se fuesen propagando es sin duda un síntoma de las intenciones de equiparación que algunos sectores sociales tuvieron durante la modernidad, pero ello no conllevó definitivamente un proceso simultáneo de erudición popular. El modelo de estudio con biblioteca, que podríamos considerar como una extensión de aquel tipo «estándar» del que hablábamos al principio del artículo por su carácter igualmente avezado, conservó intacto su aspecto -y su público demandante- a pesar de los significativos movimientos materiales que la tensión social estaba provocando en la ciudad. Después de todo, la individualidad doméstica en torno a la escritura fue seguramente la que posibilitó una configuración tan temprana de esos espacios exclusivos. Observando las bibliotecas privadas de los zaragozanos del Barroco podemos aproximarnos algo más a los requerimientos culturales del momento, a las pretensiones coleccionistas de muchos individuos, a ciertas intenciones exhibicionistas y socializadoras, pero también al

31. AHPNZ, Esteban Oloriz y Nadal, 1737, ff. 87 v.- 91 v. 
complicado universo de la introspección. La clase de persona que reivindicaba en las primeras décadas del siglo xvir un silencio sepulcral en su estudio era al fin y al cabo muchas veces la misma que mostraba a las visitas su preciado instrumento para la intelectualidad esperando a cambio signos y expresiones de complacencia y admiración; y esa misma clase de persona no cambió sus intenciones ni su modus operandi hasta mucho tiempo después.

Queda constatado entonces que el lugar predilecto para encontrar la soledad y la quietud de la lectura y de la escritura (masculinas) dentro del espacio habitable era el estudio. Sin embargo eso no debe hacernos pensar que únicamente aquellos hombres que tenían estudios en sus casas eran los que podían gozar de momentos para la reflexión; muchos casos en los que personas que contaban con libros entre sus pertenencias, no poseían en cambio lugares específicos donde poder retirarse en soledad a leerlos. Sería una solución algo drástica determinar que los individuos que no pudieron o quisieron acceder a espacios para la individualidad a lo largo de sus existencias quedaron absolutamente incapacitados para encontrar cualquier signo de abandono particular. En este sentido deberíamos aclarar que no solo los lugares, sino también los momentos, eran fundamentales para alcanzar la sustracción física y mental del mundo. De hecho, y como ya hemos podido ver, aún cuando es muy claro que la construcción de espacios para uno mismo supone una visible revolución cultural digna de ser tenida en cuenta como piedra angular de nuestro proceso evolutivo ${ }^{32}$, resulta que muchos de los que recurrían a estos medios materiales no lo hacían con la intención para la cual habían sido inicialmente diseñados (y ni siquiera en tales casos podríamos asegurar que esos individuos vivieron al margen de la intimidad o de la privacidad).

\section{LA intelectualidad COMO MEdio DE OSTENTACión. UN GABINETE Y UN CAMARÍN DE MEDIADOS DE SIGLO XVIII}

A finales del marzo de 1749, el notario José Cristóbal Villarreal llegaba a una gran casa ubicada en la calle del Coso para certificar la existencia de los lujosos bienes de la Condesa de Torresecas, Doña María Clara Díez López de Ruesta, que acababa de morir. La enorme vivienda de la Condesa viuda contaba con un gran número de habitaciones bautizadas con nombre propio cuya intencionalidad -precisamente debido al nivel tan desorbitante de objetos de gran valor material que allí podían encontrarse- en ocasiones estaba algo desvirtuada. Ese era el

32. ElíAs, N.: El proceso de la civilización. Investigaciones sociogenéticas y psicogenéticas. Madrid, Fondo de Cultura Económica, 2010.

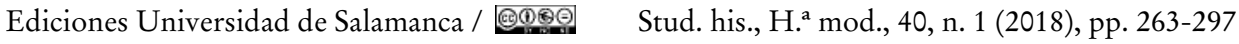


caso, sin ir más lejos, de todas aquellas habitaciones hipotéticamente destinadas al desarrollo de la intelectualidad dentro de la vivienda ${ }^{33}$.

La primera sala a la que entró el notario era el «gabinete» del palacio. El gabinete, entendido como espacio individual separado del resto dentro de las casas, comenzó a cobrar presencia en el panorama doméstico de Zaragoza hacia inicios del siglo xviII, formando parte siempre de los entramados habitacionales más complejos propios de las clases privilegiadas. Sin embargo, su intencionalidad resultaba en ocasiones algo ambigua, los útiles y muebles que comúnmente había allí resultaban ser muchas veces contradictorios entre sí, y esto era ni más ni menos por la doble significación a la que tales espacios estaban ligados en aquel momento. Según el Diccionario de Autoridades de 1734, el término «gabinete» contaba -más allá de su más principal definición, que la entendía como el «Congresso o Junta en que se tratan las materias más arcanas de Estado»-con dos acepciones distintas que, en realidad, eran prácticamente contrapuestas. La primera de ellas la tenía por «la pieza o aposento, en los Palacios o casas de los principales señores, en lo más interior de ellos, destinado a su recogimiento, o a tratar negocios particulares, y discurrir sobre ellos». Aquí se enfatizaba, pues, en el carácter masculino y privado de la estancia, así como en su necesario aislamiento respecto al resto de lugares de la casa; podemos afirmar, por tanto, que lo que estaba describiendo con esa primera llamada de la voz «gabinete» era ni más ni menos que lo que tradicionalmente se había entendido como «estudio», desde finales del siglo XvI y durante todo el siglo XviI ${ }^{34}$. Sin embargo, bastante distinta resultaba la segunda acepción del término, ya que según ella, el gabinete «Vale también la pieza que suelen tener las señoras, para peinarse y componerse: cuyas paredes suelen estar adornadas de espejos, pinturas, y figuras pequeñas, y otras semejantes buxerías que la hacen vistosa y divertida».

Había ahora, así pues, gabinetes masculinos y gabinetes femeninos, y sus funciones no tenían nada que ver la una con la otra. En el caso de la vivienda de la Condesa de Torresecas, estamos sin lugar a dudas ante un claro ejemplo de gabinete femenino; era esta una habitación destinada exclusivamente a ella, y pensada para la realización de esas inocentes actividades a las que por cuestiones de género la propietaria estaría hipotéticamente inclinada. Había allí «dos espegitos iguales

33. AHPNZ, José Cristóbal Villarreal, 1749, ff. 605 r.- 629 v.

34. En cuanto a la acepción de «estudio» dada por el mismo diccionario de 1732, lo entendía asimismo como «el aposento donde el Abogado, o el hombre erudito tiene su librería y estudia». O también, «el aposento o pieza retirada donde los Pintores, Escultúres y Architectos tienen los modelos, estampas, dibuxos y otras cosas necessarias para estudiar y entender en sus facultades». En Diccionario de Autoridades, 1732. 
con sus lunas y una tercia de largo cada uno con su marco dorado o corlado, pendientes una cinta encarnada cada uno», otras «dos lunas azogadas iguales que pueden servir para espejos», «dos espegitos pequeños iguales con su marco de madera negra $[. .$.$] guarnecida la luna de estos con espejitos en el mismo marco$ y en él unas florecillas sobrepuestas», o «dos puertecillas de christales iguales y en cada una de ellas seis que sirven para cerrar el armario que se halla embebido en la misma pared del gabinete». Ese armario servía para guardar y almacenar ordenadamente en sus diferentes compartimentos todos los vasos, platos, fuentes, jícaras y demás vajilla procedente de Talavera, de Aranda y, en su inmensa mayoría, de China. Había utensilios para el café, pomos y tarros para perfume, y varios cocos con asas de plata y pies de hueso que seguramente irían destinados a los agasajos y reuniones sociales que la Condesa organizaría en el palacio. Frente al armario se encontraba el «tocador dado de charol con su espejo delante», y en las paredes que quedaban libres de cristales y espejos, colgaban «doce láminas de bronce dorado con las efigies de los doce apóstoles grabados en madre de perla con su assita en cada una y encima de esta una reliquia con su christal delante pendiente de una lazada azul», «un quadrito o estampa con la efigie del venerable padre Gerónimo de la Compañía de Jessús con su vidrio delante», y otras «dos estampitas pequeñas iguales de papel, la una de San Francisco de Paula y la otra de San Antonio puestas ambas en sus marquitos de plomo labrado».

Queda claro entonces que el gabinete del palacio de la Condesa de Torresecas era un refugio de privacidad femenina y, al mismo tiempo, un espacio que igualmente estaría al servicio de la socialización de la mujer de la casa. No resultará extraño entonces el hecho de que, de esa misma manera, la vivienda también estuviese preparada para las reuniones masculinas y para la realización de todas aquellas actividades -individuales o grupales- que institucionalmente se entendían como propias del pater familias. El inventario nos muestra, en este sentido, la descripción de otra estancia o "camarín» que es, si la comparamos con las demás, la habitación que más se ajustaría al modelo tradicional de estudio ${ }^{35}$. Allí se almacenaban, por ejemplo, los libros de su propietario; un total de treinta

35. Las cuatro definiciones que el Diccionario de Autoridades ofrece en este caso para la voz «camarín», son igualmente ilustrativas: 1. «Aposento o sala pequeña, retirada de la común habitación, donde se guardaban diferentes buxerías, barros, vidros, porcelanas y otras alhajas curiosas y exquisitas». 2. «Por semejanza se llama el sitio donde están las alhajas que dan los devotos, para adornar las Imágenes, en especial Nuestra Señora, el qual regularmente suele hacerse detrás del Altar mismo, donde están colocadas». 3. «Se toma modernamente por lo mismo que sala pequeña, y pieza destinada, como tocador para las mugeres, la qual está adornada ricamente de diferentes cosas preciosas». 4. "Significa también la pieza retirada para el despacho, comúnmente dicha Escritorio, o Secretaría, y modernamente Gabinete». 
y dos volúmenes sin identificar que habían sido dispuestos sobre una estantería de madera pintada de negro. También había en ese camarín un gran estante con puertas en el que permanecían archivados todos «los papeles pertenecientes a la cassa», así como una espada «de golilla con su guarnición» que estaba expuesta a la vista. En cuanto a la decoración, se citaron varios espejos, una cortina de damasco verde, cuatro pinturas de santos, otro «de pintura de batalla», otros seis de «pintura de país» y, lo que es más interesante, un conjunto de casi treinta paños de raz que representaban «la Historia de Cupido», «la Historia de Troya», o directamente, otras «diversas historias». Por todo ello, la habitación denominada como «camarín» -una habitación que, además, se hallaba en un lugar privilegiado, pues estaba en la segunda planta del edificio mirando directamente al Coso-, era en primer lugar el espacio donde se guardaban los libros y donde se administraban las rentas y gestionaban los asuntos económicos relativos a la casa, y en segundo lugar también, era una plataforma de proyección simbólica llamada a lanzar mensajes claros sobre la naturaleza y posición socio-cultural del poseedor mediante la exhibición de diferentes objetos exclusivos. No debía ser casual, en este sentido, que el camarín contase también con varias sillas, bancos, taburetes y otros muebles ricos, como eran el escritorio «rebutido de ébano con sus bordes dorados y quatro nabetas en cada uno de los lados de él»; todos ellos elementos que podrían resultar beneficiosos durante el desarrollo de las reuniones y de las visitas, pero que en cambio estorbarían en gran medida a la hora de sentarse con la intención de estudiar o, simplemente, de estar en silencio.

\section{CONCLUSIÓN: LA DIVERSIFICACIÓN DEL MODELO ORIGINAL}

El modelo de estudio -o «camarín»-observado en el palacio de la Condesa de Torresecas en Zaragoza se repitió a lo largo de todo el siglo ilustrado en otras residencias majestuosas como esta. También se repitió con igual insistencia el modelo de estudio más tradicional y arquetípico, el que estaba dotado de una gran mesa, de biblioteca, de luz y de silencio para leer y estudiar. Ambos modelos, en realidad, se mantendrían de la misma forma presentes a lo largo de toda la Ilustración, pero ofreciendo nuevas variaciones que, por medio de nombres diferentes -ya no solo «estudio», sino, como hemos visto, también «gabinete», "camarín», «escritorio» o «secretaría»-, apuntarían a un cambio cultural importante que se dio mucho antes cuando, por la necesidad de aislamiento que las personas privilegiadas con requerimientos intelectuales ya reivindicaban, las casas empezaron a adaptarse fraccionando más y más sus espacios en pos de la preciada individualidad. Lo que vemos, por tanto, durante toda la modernidad y, más aún, en el transcurso del siglo xviII, es un afán por elevar la categoría de «privado» a unas cotas de riqueza

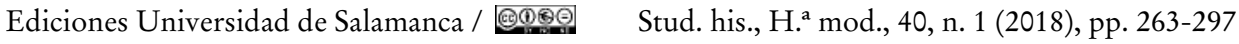


que, al menos hipotéticamente, debieron ser inabarcables para la mayoría de la población. Y decimos inabarcables porque realmente constatamos que desde muy pronto hubo sectores de la sociedad lejanos a todo privilegio que trataron de imitar de alguna forma los estilos de vida y los ritmos de consumo de las elites, forzando a estas a la nueva ideación de estrategias capaces de lograr, en última instancia, más distanciamientos materiales y simbólicos.

Consideramos también que la inclusión de los estudios en los entornos habitacionales durante el Renacimiento abrió un proceso por el cual la privacidad empezó a ser entendida como un bien alcanzable y deseado, que con los años fue adquiriendo connotaciones estrechamente ligadas a lo que se consideraba como «lo exclusivo", y que por ello fue siempre buscado, imitado y adoptado por diferentes personas de todos los sectores de la infraestructura. Ya hemos hecho alusión a que el hecho de que los estudios contribuyeran a expandir la necesidad de privacidad o recogimiento en los hogares, tampoco implicó un aumento de aquellas actividades a las que las habitaciones de los intelectuales y humanistas se dedicaron; al menos no de forma directa. La «moda» de los estudios ni ayudó a que la gente aprendiera más rápido a escribir, ni aumentó especialmente las ganas de hacerlo (incluso era relativamente común la inclusión de estudios en casas cuyos propietarios no tenían biblioteca). Por otra parte, sí que ayudó a que los espacios de la casa se dividiesen de manera que las necesidades tanto sociales como individuales de las personas pudiesen quedar finalmente satisfechas, por mucho que, como ya hemos visto, detrás de todo ello hubiese al mismo tiempo un fuerte componente misógino que tendía a escudarse en el anquilosado moralismo de la modernidad.

Los estudios de la Zaragoza de los siglos XviI y xviII fueron por todo ello la expresión de un conjunto de intenciones colectivas de orden muy distinto. El retiro y el recogimiento individual se ajustó solamente como una de esas intenciones, a pesar de que el lenguaje formal presente en esas habitaciones fuese en muchas ocasiones equivalente entre unos ejemplos y otros. Sería muy interesante poder establecer diferencias más concretas mediante el estudio detallado de bibliotecas privadas, de colecciones de pinturas, de esculturas, o de objetos devocionales y decorativos, y seguir incidiendo en estas cuestiones para recabar, en la medida de lo posible, en el conocimiento de todos aquellos elementos que, sin lugar a dudas, podemos tener por fundamentales dentro del amplio y complejo proceso de configuración cultural en nuestra sociedad. 
JUAN POSTIGO VIDAL

CREAR ESPACIOS PARA LEER Y PENSAR. LOS ESTUDIOS DE ZARAGOZA EN LOS SIGLOS XVII Y XVIII

CuAdro 1. Tinteros y aparejos para escribir en Zaragoza (siglos XVII y XVIII)

\begin{tabular}{|c|c|c|c|}
\hline Año & Nombre & Profesión & Objeto \\
\hline 1603 & $\begin{array}{l}\text { Marco Antonio de la } \\
\text { Roya }\end{array}$ & Escribano de S.M. & $\begin{array}{l}\text { Una arquimesa con su pie de nogal } 400 \\
\text { sueldos, y dentro de ella un tintero y una } \\
\text { salvadera } 12 \text { sueldos }\end{array}$ \\
\hline 1605 & Ana Esparza & $\begin{array}{l}\text { Viuda de Jerónimo } \\
\text { Oriz }\end{array}$ & $\begin{array}{l}\text { Un tintero y salvadera de bronze [dentro } \\
\text { de una arquimesa con libros de cuentas] }\end{array}$ \\
\hline 1605 & Ana de Ágreda & $\begin{array}{l}\text { Viuda de Miguel } \\
\text { López de Quinto }\end{array}$ & $\begin{array}{l}\text { Un escritorillo con tintero, sello y polvo- } \\
\text { rero }\end{array}$ \\
\hline 1606 & Diego de Córdoba & $\begin{array}{l}\text { Caballerizo del } \\
\text { arzobispo }\end{array}$ & Un tintero y polvorero \\
\hline 1608 & Simón Romeo & Mercader & Un polborero y tintero 16 sueldos \\
\hline 1612 & Joan Sisamón & Religioso & Un tintero y una salbadera de bronze \\
\hline 1612 & Carlos Ferrón & $\begin{array}{l}\text { Religioso caballero } \\
\text { de la orden de San } \\
\text { Juan de Jerusalén }\end{array}$ & Un tintero y polvorero de azófar \\
\hline 1614 & $\begin{array}{l}\text { Diego Pérez de San } \\
\text { Juan }\end{array}$ & $\begin{array}{l}\text { Infanzón ciuda- } \\
\text { dano }\end{array}$ & Un tintero y salbadera de açófar \\
\hline 1614 & $\begin{array}{l}\text { Esperanza Cerdán de } \\
\text { Escatrón }\end{array}$ & $\begin{array}{l}\text { Viuda del caballero } \\
\text { Pedro de Veamonte }\end{array}$ & $\begin{array}{l}\text { Un tintero y un polborero de plata } \\
\text { pequeños }\end{array}$ \\
\hline 1616 & Pedro Baraiz & Mercader & $\begin{array}{l}\text { Los aparejos de escribir, tinteros de } \\
\text { azófar, tixeras, cuchillo cortador y sello de } \\
\text { estudio }\end{array}$ \\
\hline 1617 & $\begin{array}{l}\text { Pedro Bermúdez de } \\
\text { Castro }\end{array}$ & & $\begin{array}{l}\text { Una salbadera y tintero de plata debaxo la } \\
\text { arquillita guarnecida con secreto }\end{array}$ \\
\hline 1618 & Andrés Peiró & Religioso & Tintero polvorero de azófar, 1 sueldo \\
\hline 1619 & $\begin{array}{l}\text { Urbano Jiménez de } \\
\text { Aragués }\end{array}$ & $\begin{array}{l}\text { Caballero conven- } \\
\text { tual de la orden } \\
\text { de San Juan de } \\
\text { Jerusalén }\end{array}$ & $\begin{array}{l}\text { Un tintero con su polvorera y con sus } \\
\text { plumas de azófar }\end{array}$ \\
\hline 1621 & Francisco Clavero & & $\begin{array}{l}\text { Un tintero y una salvadera que pesan } \\
30 \text { onças } 10 \text { arienços [en un apartado de } \\
\text { objetos de plata] }\end{array}$ \\
\hline 1623 & $\begin{array}{l}\text { Pedro Jerónimo de } \\
\text { Fres de Sola }\end{array}$ & Ciudadano & Un tintero de açófar \\
\hline 1624 & Juan Domingo Briz & Canónigo del Pilar & $\begin{array}{l}\text { Tintero, salvadera, maceta de marfil con el } \\
\text { sello de plata }\end{array}$ \\
\hline 1626 & $\begin{array}{l}\text { Gaspar Agustín de } \\
\text { Alberuela }\end{array}$ & Infanzón & Un tintero y polvorero, 8 sueldos \\
\hline
\end{tabular}

Ediciones Universidad de Salamanca / Stud. his., H.a mod., 40, n. 1 (2018), pp. 263-297 
JUAN POSTIGO VIDAL

CREAR ESPACIOS PARA LEER Y PENSAR. LOS ESTUDIOS DE ZARAGOZA EN LOS SIGLOS XVII Y XVIII

\begin{tabular}{|c|c|c|c|}
\hline Año & Nombre & Profesión & Objeto \\
\hline 1628 & Jaime de Arroyos & Canónigo de la Seo & $\begin{array}{l}\text { Un tintero, un polvorero y } 2 \text { campanillas } \\
\text { de açófar }\end{array}$ \\
\hline 1634 & $\begin{array}{l}\text { Gregorio de Aysa y } \\
\text { Lasilla }\end{array}$ & $\begin{array}{l}\text { Canónigo novicio } \\
\text { del Pilar }\end{array}$ & $\begin{array}{l}\text { Un adrezo de escribir con hilaga plateado } \\
\text { y su tintero y salbadera de açofar }\end{array}$ \\
\hline 1645 & $\begin{array}{l}\text { Juan Francisco } \\
\text { Burges }\end{array}$ & Infanzón & $\begin{array}{l}\text { Una escribanía con tintero y polborera } \\
\text { de plata y cuchara de plata y lo demás } \\
\text { del adrezo de yerro y otro adrezo más de } \\
\text { escribir de yerro } \\
{[\ldots] \text { En otro calaxe un pesico, un candado, }} \\
\text { una salvadera de tintero de azofar y diver- } \\
\text { sas escrituras }\end{array}$ \\
\hline 1646 & $\begin{array}{l}\text { Martín Gaspar Nieto } \\
\text { de Trejo }\end{array}$ & $\begin{array}{l}\text { Caballero de la } \\
\text { orden de Alcán- } \\
\text { tara, del Consejo } \\
\text { de S.M. en el Real } \\
\text { de Castilla }\end{array}$ & $\begin{array}{l}\text { Un tintero y salvadera de plata que pessan } \\
\text { un marco, } 3 \text { onças y un quarto }\end{array}$ \\
\hline 1652 & Bernardo Arrayn & $\begin{array}{l}\text { Infanzón ciuda- } \\
\text { dano }\end{array}$ & $\begin{array}{l}\text { Una escribanía de ébano y marfil pequeña } \\
\text { con su tintero y salbadera de bronze } \\
\text { tasada en quatro libras }\end{array}$ \\
\hline 1652 & Pablo Nargasia & Mercader & Un tintero y una salbadera de azófar \\
\hline 1652 & Miguel Cubels & Platero & Un tintero y salvadera de açófar \\
\hline 1655 & $\begin{array}{l}\text { Juan Francisco } \\
\text { Arguillur }\end{array}$ & Canónigo del Pilar & $\begin{array}{l}\text { Un tintero y salvadera de ocho onzas } \\
{[\ldots] \text { un tintero y salvadera de bronçe con }} \\
\text { las armas de los Arguillures valuado en } 1 \\
\text { libra } 16 \text { sueldos } \\
{[\ldots] \text { otro [estuche] negro para de camino }} \\
\text { con tintero, } 8 \text { sueldos }\end{array}$ \\
\hline 1657 & Juan Pérez & Correo & Un tintero grande de escribir \\
\hline 1658 & Jerónimo Arrayn & Licenciado & $\begin{array}{l}\text { Dos tinteros y una salvadera }[\ldots] \text { un } \\
\text { tintero de azófar con su pluma }\end{array}$ \\
\hline 1663 & Juan Gelos & Mercader & Dos tinteros y dos salvaderas de azófar \\
\hline 1663 & Pedro Guiral & Tratante & $\begin{array}{l}\text { Catorçe tinteros de hueso y cuerno } \\
\text { blancos y negros }\end{array}$ \\
\hline 1664 & Jerónimo de La Torre & Caballero noble & $\begin{array}{l}\text { Un adrezo de escribir, tintero, salvadera y } \\
\text { ostiera con su covertera y una campanilla, } \\
\text { todo de plata que con el plomo del tintero } \\
\text { ha pesado todo treynta y seys onzas } \\
\text { [...] Un adrezo de escribir, tintero, ostiera } \\
\text { y polborera de plata todo junto, una } \\
\text { campanilla, una palmatoria y dos bujías } \\
\text { de plata, pesó todo treynta y una onzas y } \\
\text { media }\end{array}$ \\
\hline
\end{tabular}

Ediciones Universidad de Salamanca / 
JUAN POSTIGO VIDAL

CREAR ESPACIOS PARA LEER Y PENSAR. LOS ESTUDIOS DE ZARAGOZA EN LOS SIGLOS XVII Y XVIII

\begin{tabular}{|c|c|c|c|}
\hline Año & Nombre & Profesión & Objeto \\
\hline 1667 & Andrés de Subiza & $\begin{array}{l}\text { Alcaide de las } \\
\text { cárceles de la } \\
\text { Inquisición }\end{array}$ & $\begin{array}{l}\text { Trece piedras, tintero y salbadera, treinta } \\
\text { reales }[\ldots] \text { un tintero y salbadera de } \\
\text { bronce, } 16 \text { sueldos }\end{array}$ \\
\hline 1691 & Andrés Balanrategui & $\begin{array}{l}\text { Tesorero y digni- } \\
\text { dad de la Seo }\end{array}$ & $\begin{array}{l}\text { Una escribanía de concha y ébano y marfil } \\
\text { con esquinas de feligrana en plata con } \\
\text { tintero, salvadera, tixeras, cuchillo, todo } \\
\text { con cavos de concha y filigrana de plata }\end{array}$ \\
\hline 1701 & Juan Francisco Calvo & $\begin{array}{l}\text { Mayordomo de } \\
\text { los Duques de } \\
\text { Villahermosa }\end{array}$ & Dos tinteros y dos salvaderas de azófar \\
\hline 1705 & $\begin{array}{l}\text { Pascual Torres y } \\
\text { Montaner }\end{array}$ & Mancebo hidalgo & $\begin{array}{l}\text { Una libra y quatro sueldos jaqueses en un } \\
\text { tintero y polvarera grandes de bronce }\end{array}$ \\
\hline 1706 & Juan Baltasar & $\begin{array}{l}\text { Presbítero racio- } \\
\text { nero de la Seo }\end{array}$ & $\begin{array}{l}\text { Un adrezo de escribir de plata, tintero, } \\
\text { polborera y ostiero que pesa catorze onzas } \\
\text { y seis arienzos }\end{array}$ \\
\hline 1710 & Jaime Franze & $\begin{array}{l}\text { Presbítero de la } \\
\text { Magdalena }\end{array}$ & Un tintero de faldriquera negra \\
\hline 1718 & Hipólito Juan Pomes & $\begin{array}{l}\text { Infanzón maestro } \\
\text { tafetanero }\end{array}$ & $\begin{array}{l}\text { Un tintero y una salvadera de azófar y una } \\
\text { ymagen de tierra }\end{array}$ \\
\hline 1725 & Isabel García & $\begin{array}{l}\text { Viuda de Barto- } \\
\text { lomé de Campos }\end{array}$ & Un tintero y salbadera de nogal \\
\hline 1725 & $\begin{array}{l}\text { Félix Perfecto Casa- } \\
\text { lete y de Abos }\end{array}$ & $\begin{array}{l}\text { Presbítero arci- } \\
\text { preste de la Seo }\end{array}$ & $\begin{array}{l}\text { Un juego de tintero, salbadera y caxa de } \\
\text { oblea con sus tapes }\end{array}$ \\
\hline 1729 & Juan Lucas & $\begin{array}{l}\text { Presbítero benefi- } \\
\text { ciado del Pilar }\end{array}$ & Un tintero y una salbadera de azófar \\
\hline 1730 & Juan Duzón & $\begin{array}{l}\text { Presbítero racio- } \\
\text { nero del Pilar }\end{array}$ & Tintero y salvadera de estaño \\
\hline 1731 & María Ignacia Quadre & $\begin{array}{l}\text { Mujer de Ventura } \\
\text { Urtado }\end{array}$ & $\begin{array}{l}\text { Un tintero, una salbadera y una oblera de } \\
\text { peltre }\end{array}$ \\
\hline 1737 & $\begin{array}{l}\text { Baltasar Jimeno y } \\
\text { Moliner }\end{array}$ & Canónigo del Pilar & $\begin{array}{l}\text { Un tintero de plomo con salvadera de lo } \\
\text { mismo y una caja para oblea de oja de lata } \\
\text { y un sello de metal; otro tintero de azófar } \\
\text { y salvadera de lo mismo; otro tintero de } \\
\text { piedra jaspeada }\end{array}$ \\
\hline 1737 & José Antonio Cebrián & $\begin{array}{l}\text { Infanzón y } \\
\text { causídico de la } \\
\text { Real Audiencia del } \\
\text { Reino }\end{array}$ & $\begin{array}{l}\text { Un tablero de estudio con seis cajones, } \\
\text { tintero y salvadera }\end{array}$ \\
\hline 1738 & Esteban Jiménez & & $\begin{array}{l}\text { Un tintero y salvadera de plata y sello de } \\
\text { lo mismo }\end{array}$ \\
\hline
\end{tabular}

Ediciones Universidad de Salamanca / 
JUAN POSTIGO VIDAL

CREAR ESPACIOS PARA LEER Y PENSAR. LOS ESTUDIOS DE ZARAGOZA EN LOS SIGLOS XVII Y XVIII

\begin{tabular}{|c|c|c|c|}
\hline Año & Nombre & Profesión & Objeto \\
\hline 1740 & Jaime Pumar & Presbítero & Un tintero y una salvadera de bronce \\
\hline 1741 & Lorenzo de Esparza & Maestro tafetanero & Un tintero con su salvadera de bronze \\
\hline 1742 & Juan Yllera & $\begin{array}{l}\text { Presbítero racio- } \\
\text { nero de la Seo }\end{array}$ & Un tintero y salvadera grandes de estaño \\
\hline 1742 & $\begin{array}{l}\text { Alejandro de la Cerda } \\
\text { y Granada }\end{array}$ & $\begin{array}{l}\text { Caballero hijo- } \\
\text { dalgo }\end{array}$ & $\begin{array}{l}\text { Una escupidera, palmatoria, tinteros, dos } \\
\text { campanas, una vazinilla y otras piezezue- } \\
\text { las crebadas, todo ochenta y dos onzas }\end{array}$ \\
\hline 1743 & Jerónimo Belarde & & $\begin{array}{l}\text { Un tintero pequeño ordinario de faldri- } \\
\text { quera }\end{array}$ \\
\hline 1744 & Antonio Pastor & $\begin{array}{l}\text { Beneficiado de la } \\
\text { Magdalena }\end{array}$ & Un tintero, salbadera y plumera de bronze \\
\hline 1746 & Diego Losilla & $\begin{array}{l}\text { Presbítero y bene- } \\
\text { ficiado }\end{array}$ & Un tintero y salvadera de bronze viejos \\
\hline 1749 & $\begin{array}{l}\text { María Clara Díez } \\
\text { López de Ruesta }\end{array}$ & $\begin{array}{l}\text { Condesa viuda de } \\
\text { Torresecas }\end{array}$ & $\begin{array}{l}\text { Seis macerinas, una escribanía que se } \\
\text { compone de tintero, salbadera, obleera, } \\
\text { campana y cañón para luz, tres escudillas } \\
\text { con sus asas, uno y otro de plata, el peso } \\
\text { de todo en junto es de ciento treinta y } \\
\text { siete onzas y dos quartos; una escribanía } \\
\text { de tapa negra forrada por dentro en tercio- } \\
\text { pelo berde con tres piececitas sueltas de } \\
\text { tintero, salbadera y obleera de plata muy } \\
\text { pequeñas y sencillas }\end{array}$ \\
\hline 1751 & Jorge de Sola Piloa & $\begin{array}{l}\text { Escribano de } \\
\text { cámara }\end{array}$ & $\begin{array}{l}\text { Un tinterito de porzelana pequeño y una } \\
\text { caxa de oblea de peltre }\end{array}$ \\
\hline 1754 & $\begin{array}{l}\text { Jaime Pedro } \\
\text { Mezquita }\end{array}$ & $\begin{array}{l}\text { Regidor de la } \\
\text { ciudad }\end{array}$ & $\begin{array}{l}\text { Un tintero y salvadera; un tintero, una } \\
\text { salbadera y caja correspondiente para } \\
\text { poner obleas, estas tres pieças son de plata }\end{array}$ \\
\hline 1754 & $\begin{array}{l}\text { Juan Antonio Lanuza } \\
\text { y Bujadors Gisabert }\end{array}$ & $\begin{array}{l}\text { Conde de Plasen- } \\
\text { cia, grande de } \\
\text { España }\end{array}$ & $\begin{array}{l}\text { Una escribanía de plata sin platillo que se } \\
\text { compone de quatro piezas, tintero, salba- } \\
\text { dera, plumera, y oblehera, las dos de estas } \\
\text { con tapes echura antigua y todas piezas } \\
\text { pequeñas }\end{array}$ \\
\hline 1755 & Joseph Gutiérrez & $\begin{array}{l}\text { Maestro torcedor } \\
\text { de seda }\end{array}$ & Un tintero de plomo y salbadera de cobre \\
\hline 1755 & $\begin{array}{l}\text { Joseph Marín y Ana } \\
\text { de Fuentes }\end{array}$ & & Un tintero quadrado \\
\hline 1759 & $\begin{array}{l}\text { Francisco Calaf y } \\
\text { Puchol }\end{array}$ & $\begin{array}{l}\text { Abogado de los } \\
\text { Reales Consejos de } \\
\text { S.M. }\end{array}$ & $\begin{array}{l}\text { Un tintero y una salbadera de estaño; unos } \\
\text { tinteros guarnecidos de espejuelos }\end{array}$ \\
\hline
\end{tabular}

Ediciones Universidad de Salamanca / 
JUAN POSTIGO VIDAL

CREAR ESPACIOS PARA LEER Y PENSAR. LOS ESTUDIOS DE ZARAGOZA EN LOS SIGLOS XVII Y XVIII

\begin{tabular}{|c|c|c|c|}
\hline Año & Nombre & Profesión & Objeto \\
\hline 1762 & Miguel Perales & & $\begin{array}{l}\text { Una tohalla de comunión de true con } \\
\text { encaxes alrededor buena y tintero y salba- } \\
\text { dera de bronze }\end{array}$ \\
\hline 1764 & Enrique Clavero & Noble de Aragón & $\begin{array}{l}\text { Una escribanía de sobremesa y un tintero } \\
\text { de madera }\end{array}$ \\
\hline 1765 & Joseph Bura & $\begin{array}{l}\text { Presbítero benefi- } \\
\text { ciado de San Gil }\end{array}$ & $\begin{array}{l}\text { Un tintero y salvadera de peltre; una } \\
\text { vidrierita de una tercia en quadro y un } \\
\text { tintero grande de piedra jaspe }\end{array}$ \\
\hline 1766 & $\begin{array}{l}\text { Joseph de la Cabra } \\
\text { y Dava Vives de } \\
\text { Cañamás }\end{array}$ & Noble de Aragón & $\begin{array}{l}\text { Un platillo para vinageras de rompimiento } \\
\text { con tintero, campana, salvadera, plumero } \\
\text { y oblechero, su peso quareinta y siete } \\
\text { onzas y doce arienzos }\end{array}$ \\
\hline 1771 & $\begin{array}{l}\text { Francisco Antonio } \\
\text { Comenge }\end{array}$ & Infanzón & Dos juegos de tinteros de peltre, 2 libras \\
\hline 1771 & Antonio de Ara & & $\begin{array}{l}\text { Una escrivanía de plata que se compone } \\
\text { de tres piezas sueltas como son tintero, } \\
\text { salbadera y ostiero con su tape cada una }\end{array}$ \\
\hline 1773 & María Ángela Buver & $\begin{array}{l}\text { Viuda de Sebastián } \\
\text { Rodolffe, coronel } \\
\text { del cuerpo de } \\
\text { ingenieros }\end{array}$ & Un tintero, salvadera y oblera de peltre \\
\hline 1773 & Miguel Juan Abadía & Colegial albeitar & $\begin{array}{l}\text { Un tintero y salbadera de metal viejos y } \\
\text { una escovilla usada }\end{array}$ \\
\hline 1777 & $\begin{array}{l}\text { Pedro de Orús y } \\
\text { Amada }\end{array}$ & & $\begin{array}{l}\text { Una mampara y un juego de tinteros de } \\
\text { peltre }\end{array}$ \\
\hline 1779 & Isabel Ubieto & Viuda de mercader & Un tintero con su salbadera de azófar \\
\hline 1784 & $\begin{array}{l}\text { Bartolomé Yturralde } \\
\text { y Novales }\end{array}$ & & Un juego de tinteros de bronze \\
\hline 1785 & Juan de San Martín & $\begin{array}{l}\text { Familiar de la } \\
\text { Inquisición }\end{array}$ & $\begin{array}{l}\text { Un tintero, dos salvaderas y un obleero, } \\
12 \text { [reales de plata] }\end{array}$ \\
\hline 1790 & Manuela de Boyra & $\begin{array}{l}\text { Viuda de Joaquín } \\
\text { de Fuentes }\end{array}$ & $\begin{array}{l}\text { Un tintero viexo de plomo; un tintero de } \\
\text { oja de lata con sus divisiones; un tintero y } \\
\text { salbadera de baxilla del Conde de Aranda }\end{array}$ \\
\hline 1790 & $\begin{array}{l}\text { Pedro Espinosa y } \\
\text { Fuentes }\end{array}$ & $\begin{array}{l}\text { Arcediano de } \\
\text { Belchite }\end{array}$ & $\begin{array}{l}\text { Una escribanía que parece de plata y se } \\
\text { compone de plato, tintero, salbadera, } \\
\text { oblehera, campana y caño para las plumas } \\
\text { con sus tapes correspondientes }\end{array}$ \\
\hline 1797 & Usbaldo López & & $\begin{array}{l}\text { Un tintero de oja de lata con sus divisio- } \\
\text { nes para poner los polvos y oblea }\end{array}$ \\
\hline
\end{tabular}

Ediciones Universidad de Salamanca / Stud. his., H.a mod., 40, n. 1 (2018), pp. 263-297 
JUAN POSTIGO VIDAL

CREAR ESPACIOS PARA LEER Y PENSAR. LOS ESTUDIOS DE ZARAGOZA EN LOS SIGLOS XVII Y XVIII

\begin{tabular}{|c|l|l|l|}
\hline Año & \multicolumn{1}{|c|}{ Nombre } & \multicolumn{1}{c|}{ Profesión } & \multicolumn{1}{c|}{ Objeto } \\
\hline 1798 & Antonio Lafiguera & $\begin{array}{l}\text { Prior de la Real } \\
\text { Audiencia del } \\
\text { Reino }\end{array}$ & $\begin{array}{l}\text { Dos tinteros de volsillo de asta; dos juegos } \\
\text { de tinteros de peltre }\end{array}$ \\
\hline 1798 & $\begin{array}{l}\text { María Francisca } \\
\text { de Sales Portoca- } \\
\text { rrero Fernández de } \\
\text { Córdoba Leiva y } \\
\begin{array}{l}\text { Lacerda Funes de } \\
\text { Villalpando }\end{array}\end{array}$ & $\begin{array}{l}\text { Condesa de } \\
\text { Montijo y Baños, } \\
\text { Marquesa de Leiva } \\
\text { y Osera }\end{array}$ & $\begin{array}{l}\text { Tres juegos de tinteros de peltre, pero el } \\
\text { uno no tiene oblehera ni salvadera }\end{array}$ \\
\hline
\end{tabular}

\section{Bibliografía}

Abad Zardoya, C.: «Donde el arte debe sujetarse a la necesidad. Intendencia doméstica, sociabilidad y apartamentos masculinos en los entresuelos del siglo XVIII», en Franco Rubio, G.: La vida de cada dia. Rituales, costumbres y rutinas cotidianas en la España moderna. Madrid, Almudayna, 2012, pp. 113-134.

Ago, R.: Il gusto delle cose. Una storia degli oggetti nella Roma del Seicento. Roma, Donzelli Editore, 2006.

Ariès, P. y Duby, G. (dir.): Historia de la vida privada. 3. Del Renacimiento a la Ilustración. Madrid, Taurus, 2001.

Bartolomé Bartolomé, J. M.: «Niveles de riqueza patrimonial, condiciones de vida y pautas de consumo de las familias de comerciantes y financieros de la ciudad de León (1700-1850)», en Chacón Jiménez, F. y Gómez Carrasco, C. J. (coords.): Familias, recursos bumanos y vida material. Murcia, Servicio de Publicaciones, 2014, pp. 181-199.

Bartolomé Bartolomé, J. M.: «Consumos y apariencias externas de las familias de la burguesía leonesa (1700-1850)», Studia Historica. Historia Moderna, 37, 2015, pp. 269-290.

Baulant, M.: «Typologie des inventaires après décès», en VAn Der Woude, A. D. y Schuurman, A. (eds.): Probate inventoires. A new source for the historical study of wealth, material culture and agricultural development. Utrecht, HES, 1980, pp. 33-42.

Blasco Esquivias, B. (dir.): La casa. Evolución del espacio doméstico en España. Volumen 1. Edad Moderna. Madrid, Ediciones El Viso, 2006.

Bleichmar, D. y Mancall, P. C.: Collecting across cultures. Material exchanges in the Early Modern Atlantic World. Philadelphia, University of Pennsylvania Press, 2011.

Blom, P.: To have and to hold. An intimate history of collectors and collecting. Nueva York, Overlook Press, 2003.

Braudel, F.: Civilización material, economía y capitalismo, siglos XV-XVIII. Tomo 1. Las estructuras de lo cotidiano: lo posible y lo imposible. Madrid, Alianza, 1984.

Brewer, J. y Porter, R. (eds.): Consumption and the World of Goods. Londres-Nueva York, Routledge, 1993. 
JUAN POSTIGO VIDAL

CREAR ESPACIOS PARA LEER Y PENSAR. LOS ESTUDIOS DE ZARAGOZA EN LOS SIGLOS XVII Y XVIII

Brewer, J. y Bermingham, A.: The consumption of culture, 1600-1800. Image, object and text. Londres, Routledge, 1995.

Campbell, S. J.: The Cabinet of Eros. Reinassance Mythological Painting and the Studiolo of Isabella d'Este. New Haven y Londres, Yale University Press, 2004.

Cano de Gardoqui, J. L.: Tesoros y colecciones. Orígenes y evolución del coleccionismo artístico. Valladolid, Universidad de Valladolid, 2001.

Cornette, J.: «La Révolution des objects. Le París des inventaires après déces (xvire-XviIIe sièclees)», Revue d'Histoire Moderne et Contemporaine, XXXVI, 1989, pp. 476-486.

Currie, E.: «The Study: Business and Pleasure», en Currie, E.: Inside the Renaissance House. Londres, V\&A, 2010, pp. 69-94.

Elías, N.: El proceso de la civilización. Investigaciones sociogenéticas y psicogenéticas. Madrid, Fondo de Cultura Económica, 2010.

Elsner, J. y Cardinal, R.: The Cultures of Collecting. Cambridge, Harvard University Press, 1994.

Fernández Clemente, E.: Estudios sobre la Ilustración aragonesa, Zaragoza, Institución «Fernando el Católico», 2005.

Franceschi, F.: «Business Activities», en Ajamar-Wollheim, M. y Dennis, F. (eds.): At bome in Renaissance Italy. Londres, V\&A, 2006, pp. 166-172.

Franco Rubio, G.: «La vivienda en el Antiguo Régimen: de espacio habitable a espacio social», Chronica Nova, 35, 2009, pp. 63-103.

García Fernández, M. (dir.): Cultura material y vida cotidiana moderna: escenarios. Madrid, Sílex, 2013.

García Fernández, M. y Dos Guimaraes Sá, I. (dir.): Portas adentro. Comer, vestir e babitar na Península Ibérica (ss. XVI-XIX). Salamanca, Universidade de Coimbra, Universidad de Valladolid, 2010.

García Fernández, M. y Bartolomé Bartolomé, J. M. (dirs.): Apariencias contrastadas, contraste de apariencias. Cultura material y consumos de Antiguo Régimen. León, Universidad, 2012.

GómEz URDÁÑEZ, C.: «Entre erudición y naturaleza, arquitectura. La casa de Juan Vicencio Lastanosa», en VV. AA.: Vicencio Juan de Lastanosa (1607-1681). La pasión de saber. Huesca, Instituto de Estudios Altoaragoneses, 2007, pp. 59-67.

Gurevich, A.: Los orígenes del individualismo europeo. Barcelona, Crítica, 1997.

Icíar, J.: Arte subtilíssima por la qual se enseña a escrevir perfectamente. Juan de Icíar y Juan de Vingles, 1522.

Impey, O. y MacGregor, A.: The Origins of Museums: The Cabinet of Curiosities in Sixteenth-and Seventeenth-Century Europe. Oxford, Oxford University Press, 1985.

Kaufmann, T.: The Mastery of Nature: Aspects of Art, Science and Humanism in the Renaissance. Princeton, Princeton University Press, 1993.

Lugli, A.: Wunderkammer: la stanza della meraviglia. Turín, Allemandi, 1997.

Lugli, A.: Naturalia et mirabilia: les cabinets de curiosites en Europe. París, Adam Biro, 1998.

Maistre, J.: Viaje alrededor de mi cuarto. Buenos Aires, Espasa-Calpe, 1950.

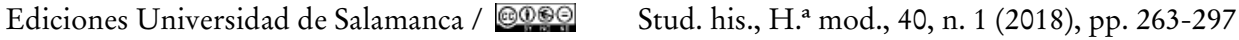


Martín, A. (Coord.): Hacer historia desde Simancas. Homenaje a José Luis Rodríguez de Diego. Valladolid, Junta de Castilla y León, 2011.

Martínez Góngora, M.: La utilización masculina del espacio doméstico rural en textos españoles del Renacimiento. Vigo, Editorial Academia del Hispanismo, 2010, pp. 48-49.

Mattoso, J. (Dir.): História da Vida Privada em Portugal. Lisboa, Círculo de Leitores y Temas e Debates, 2011.

Mauriès, P: Cabinets of Curiosities. Nueva York, Thames and Hudson, 2002.

Morán Turina, J. M. y Checa, F.: El coleccionismo en España: de la cámara de maravillas a la galería de pinturas. Madrid, Cátedra, 1985.

Muensterberger, W.: Collecting: an unruly passion. Psychological perspectives. Nueva York-Londres, Harcourt Brace \& Co., 1995.

Pardailhé-Galabrun, A.: La naissance de l'intime. 3000 foyers parisiens, XVII-XVIII siècles. París, Presses Universitaires de France, 1988.

Postigo Vidal, J.: La vida fragmentada. Experiencias y tensiones cotidianas en Zaragoza (siglos XVII y XVIII). Zaragoza, Institución «Fernando el Católico», 2015.

Postigo Vidal, J.: «El estudio como espacio para la intimidad, la intelectualidad y la masculinidad en Zaragoza durante la Edad Moderna», en Serrano Martín, E. (coord.): De la tierra al cielo. Lineas recientes de investigación en Historia Moderna. Zaragoza, Institución «Fernando el Católico», 2013, pp. 1.067-1.082.

Pounds, N. J. G.: La vida cotidiana: Historia de la cultura material. Barcelona, Crítica, 1999.

Roche, D.: Histoire des choses banales. Naissance de la société de consommation, XVIIIe-XIXe siècles. París, Fayard, 1997.

SARTI, R.: Vida en familia. Casa, comida y vestido en la Europa Moderna. Barcelona, Crítica, 2002.

SCHLOSSER, J. von: Las cámaras artísticas y maravillosas del Renacimiento tardío. Una contribución a la bistoria del coleccionismo. Madrid, Akal, 1988.

Schuurman, A. y Walsh, L. (Eds.): Material culture: Consumption, Life-style, standard of Living, 1500-1900. Eleventh International Economic History Congress, Milán, 1994.

Sobrado Correa, H.: «Los inventarios post-mortem como fuente privilegiada para el estudio de la Historia de la Cultura Material en la Edad Moderna», Hispania, LXIII/3, núm. 215, 2003, pp. 825-861.

Thornton, D.: The Scholar in his Study. Ownership and Experience in Renaissance Italy. New Haven y Londres, Yale University Press, 1997.

Torío de la Riva y Herrero, T.: Arte de escribir por reglas y con muestras. Madrid, Viuda de Joaquín Ibarra, 1798, p. 97.

Waro-Desjardins, F.: La vie quotidienne dans le Vexin au XVIIIe siècle. Dans l'intimité d'une societé rurale (d'après les inventaires après décès de Genainville (1736-1810), Pontoise, Éditions du Valhermeil, 1992.

Welch, E.: De compras en el Renacimiento. Culturas del consumo en Italia, 1400-1600. Valencia, Universitat de València, 2009. 
Yun Casalilla, B. y Torras, J. (dirs.): Consumo, condiciones de vida y comercialización: Cataluña, Castilla, siglos XVII-XIX. Junta de Castilla y León, Consejería de Educación y Cultura, 1999.

Yun Casalilla, B.: «Consumo, mercados y sociedades: Sobre la historia económica de la Europa del Antiguo Régimen y la formación de una identidad europea», en MARcos Martín, A. (coord.): Hacer historia desde Simancas. Homenaje a José Luis Rodríguez de Diego. Valladolid, Junta de Castilla y León, 2011.

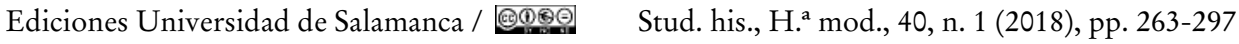

